\title{
Contribution of acidic components to the total acid number (TAN) of bio-oil
}

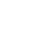

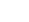

\author{
Lydia K-E. Park, ${ }^{1}$ Jiaojun Liu, ${ }^{1}$ Sotira Yiacoumi, ${ }^{1}$ Abhijeet P. Borole,,${ }^{2,3}$ Costas Tsouris ${ }^{*}, 1,3$
}

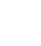

${ }^{1}$ Georgia Institute of Technology, Atlanta, Georgia 30332-0373, United States

${ }^{2}$ Bredesen Center for Interdisciplinary Research and Education, The University of Tennessee,

Knoxville, Tennessee 37996-4514, United States

${ }^{3}$ Oak Ridge National Laboratory, Oak Ridge, Tennessee 37831-6181, United States

*Corresponding author: E-mail: tsourisc@ornl.gov;

Telephone: 865-241-3246; Fax: 865-241-4829

Telephone. 865-241-3246, Fax. 865-241-4829

4

March 2017

6

\section{Revised Manuscript}

\author{
Submitted to FUEL
}

Notice: This manuscript has been authored by UT-Battelle, LLC under Contract No. DE-AC0500OR22725 with the US Department of Energy. The United States Government retains and the publisher, by accepting the article for publication, acknowledges that the United States Government retains a non-exclusive, paid-up, irrevocable, world-wide license to publish or reproduce the published form of this manuscript, or allow others to do so, for United States Government purposes. The Department of Energy will provide public access to these results of federally sponsored research in accordance with the DOE Public Access Plan (http://energy.gov/downloads/doe-public-access-plan). 
29 Abstract

30 Bio-oil or pyrolysis oil - a product of thermochemical decomposition of biomass under oxygen-limited

31 conditions - holds great potential to be a substitute for nonrenewable fossil fuels. However, its high

32 acidity, which is primarily due to the degradation of hemicelluloses, limits its applications. For the

33 evaluation of bio-oil production and treatment, it is essential to accurately measure the acidity of bio-oil.

34 The total acid number (TAN), which is defined as the amount of potassium hydroxide needed to titrate

35 one gram of a sample and has been established as an ASTM method to measure the acidity of petroleum

36 products, has been employed to investigate the acidity of bio-oil. The TAN values of different

37 concentrations of bio-oil components such as standard solutions of acetic acid, propionic acid, vanillic

38 acid, hydroxybenzoic acid, syringic acid, hydroxymethylfurfural, and phenol were analyzed according to

39 the ASTM D664 standard method. This method showed the same linear relationship between the TAN

40 values and the molar concentrations of acetic, propionic, and hydroxybenzoic acids. A different linear

41 relationship was found for vanillic acid, due to the presence of multiple functional groups that can

42 contribute to the TAN value. The influence of the titration solvent on the TAN values has been

43 determined by comparing the TAN values and titration curves obtained from the standard method with

44 results from the TAN analysis in aqueous environment and with equilibrium modeling results. Aqueous

45 bio-oil samples with a known amount of acetic acid added were also analyzed. The additional acetic acid

46 in bio-oil samples caused a proportional increase in the TAN values. The results of this research indicate

47 that the TAN value of a sample with acids acting as monoprotic acids in the titration solvent can be

48 converted to the molar concentration of total acids. For a sample containing acids that act as diprotic and

49 polyprotic acids, however, its TAN value cannot be simply converted to the molar concentration of total

50 acids because these acids have a stronger contribution to the TAN values than the contribution of

51 monoprotic acids. 
52 Keywords

53 Total acid number (TAN); bio-oil acidity; switchgrass bio-oil; biofuel

54 


\section{Introduction}

56 Increasing energy demand, climate change, and carbon dioxide emissions from fossil fuels raise serious

57 concerns. The exploration, marketing, and transportation of fossil fuels cause additional pollution as well

58 as social and political unrest [1]. In light of these circumstances, carbon-neutral biofuels produced from

59 various lignocellulosic materials such as grass, wood, agricultural, or forest residues appear to be a

60 promising substitute for fossil fuels. The currently available forms of biofuels include bioethanol,

61 biodiesel, and bio-oil (pyrolysis oil).

62

63 Bioethanol and biodiesel are commercially used in blends of gasoline and diesel, respectively, for vehicle-

64 use and heating. Bio-oil is produced, along with byproducts such as char and syngas, from pyrolysis in

65 which biomass is heated under oxygen-limited conditions. Currently, bio-oil is the cheapest biofuel

66 produced from lignocellulosic materials, with good potential of becoming a sustainable energy source [2].

67 However, it has some application-hindering properties including high moisture content, high viscosity,

68 high density, low heating value, and high acidity.

69

70 High acidity is especially problematic for the storage and transportation of bio-oil, which has a typical $\mathrm{pH}$

71 of 2-3 [3-5]). Acidic components can also cause instability by generating protons $\left(\mathrm{H}^{+}\right)$that can promote

72 condensation and polymerization reactions [6]. Hence, there have been various attempts to reduce the

73 acidity through neutralization and catalytic reactions [6-8]. One approach to neutralizing acidic bio-oil is

74 by adding alkaline solution [8]. To properly compare initial and final bio-oils after a neutralization

75 treatment, however, the acidity of bio-oil must be accurately quantifiable.

76

77 Various techniques have been employed to measure the acidity of bio-oil including $\mathrm{pH}$, ion

78 chromatography (IC), high-performance liquid chromatography (HPLC), and gas chromatography-mass

79 spectrometry (GC-MS), though each technique has some limitations. The $\mathrm{pH}$, which measures the

80 concentration of protons, does not provide the concentrations of acidic components, and also is found to 
81 be susceptible to errors [9]. Chemical analysis using IC, HPLC, and GC-MS can identify and quantify

82 various chemicals including acids in bio-oil samples [5, 10]. There are, however, some disadvantages

83 associated with these techniques. Small changes in $\mathrm{pH}$ can greatly affect IC results by altering the binding

84 profiles of IC resins [11]. On the other hand, HPLC and GC-MS may underestimate the acidic

85 components in bio-oil samples. Specifically, GC-MS is known to detect only volatile compounds (e.g.,

86 acetic acid and propionic acid), which comprise $25-40 \mathrm{wt} \%$ of bio-oil, while other heavy carboxylic

87 acids may not be detected [12]. Moreover, due to a high diversity of chemicals in bio-oil, the use of

88 HPLC and GC-MS has been linked to measurement inconsistencies among different laboratories, as

89 demonstrated through the round-robin testing by Oasmaa et al. [9]. Although recently Oasmaa et al. [4]

90 suggested that capillary electrophoresis (CE) can accurately measure the acidic components in bio-oil, CE

91 has disadvantages of lower injection precision and sensitivity as compared to HPLC [13]. Moreover,

92 chemical analysis, in general, cannot provide a single parameter that can be used for comparing samples

93 with different chemical compositions.

94

95 Regardless of differing characteristics between various bio-oil samples, the total acid number (TAN)

96 analysis can provide a single parameter that can be used for acidity comparisons. TAN is the amount of

97 potassium hydroxide $(\mathrm{KOH}$, in milligram) required to titrate one gram of a sample. The TAN analysis

98 was originally developed for measuring the acidity of petroleum products but has been applied more

99 recently to measure the acidity of biodiesel [14-23], biodiesel blends [15, 16, 20], vegetable oils [18, 24],

100 lubricating oils [25], heavy oil [26], bitumens [26], fats [24], and bio-oil [4, 9, 12, 27].

101

102 The current standard on biodiesel acidity is $0.50 \mathrm{mg} \mathrm{KOH} / \mathrm{g}$, according to the American Society for

103 Testing and Materials (ASTM) D644 and European Standard (EN) 14104 [20]. However, currently, there

104 is no available standard for bio-oil. The typical TAN value of switchgrass intermediate pyrolysis bio-oil is

$105137.4 \pm 3.0 \mathrm{mg} \mathrm{KOH} / \mathrm{g}$ [5], which is high compared to the standard for biodiesel.

106 
107 Today, various standard methods (summarized in Table 1 for comparison) are available to measure the

108 TAN. Largely, there are potentiometric (ASTM D664 [28]) and colorimetric methods (ASTM D974 [29],

109 ASTM D3339 [30], and American Oil Chemists' Society, AOCS Cd 3d 63 [31]). The colorimetric

110 methods are known to be simple and better than potentiometric methods [15, 22]. Moreover, the

111 colorimetric methods (ASTM D974 [29], EN14104 [32], and AOCS Cd 3d-63 [31]) were found to be

112 more accurate for biodiesel analysis because these methods avoid errors introduced by the electrode [15,

113 22]. The aqueous titration from EN14104, however, can cause some ester bonds to be hydrolyzed by the

114 aqueous base, leading to consumption of base and elevating measurements [20]. Furthermore, the end

115 point determination in colorimetric methods can be challenging [14, 19]. Although ASTM D974 is known

116 to be compatible for a colored sample, the dark brown (nearly black) color of bio-oil would most likely

117 interfere with the endpoint determination during the analysis. Thus, for bio-oil analysis, the

118 potentiometric method (ASTM D664 [28]) would be the appropriate option.

119

120

Table 1. Standard methods of acidity analysis

\begin{tabular}{|c|c|c|c|c|}
\hline Standards & $\begin{array}{c}\text { ASTM D664-11a } \\
\text { [28] }\end{array}$ & ASTM D974-14 & ASTM D3339-12 & AOCS Cd 3d 63 \\
\hline Methods & Potentiometric & Colorimetric & Colorimetric & Colorimetric \\
\hline Alkaline of titrant & $\mathrm{KOH}$ & $\mathrm{KOH}$ & $\mathrm{KOH}$ & $\mathrm{KOH}$ \\
\hline Solution for titrant & isopropanol & isopropanol & isopropanol & isopropanol \\
\hline $\begin{array}{l}\text { Concentration of } \\
\text { titrant }(\mathrm{M})\end{array}$ & 0.1 & 0.02 & 0.01 & 0.1 \\
\hline Titration solvent & $\begin{array}{c}\text { toluene:isopropanol: } \\
\text { water }\end{array}$ & toluene:isopropanol & $\begin{array}{c}\text { toluene:isopropanol: } \\
\text { water }\end{array}$ & toluene:isopropanol \\
\hline $\begin{array}{c}\text { Solvent volume } \\
\text { Ratio }\end{array}$ & 100:99:1 & $1: 1$ & 100:99:1 & $1: 1$ \\
\hline $\begin{array}{l}\text { Titration solvent } \\
\qquad(\mathrm{mL})\end{array}$ & 125 & 10 & 40 & 125 \\
\hline Indicator & $\mathrm{n} / \mathrm{a}$ & p-naphtholbenzein & p-naphtholbenzein & phenolphthalein \\
\hline Amount of indicator & $\mathrm{n} / \mathrm{a}$ & 8 drops & & $\begin{array}{l}\text { until the appearance of } \\
\text { a slightly pink color }\end{array}$ \\
\hline $\begin{array}{l}\text { Sample weight } \\
\text { range }(\mathrm{g})\end{array}$ & $0.1-20$ & $0.2-20$ & $0.1-5$ & Varies \\
\hline $\begin{array}{l}\text { TAN ranges } \\
(\mathrm{mg} \mathrm{KOH} / \mathrm{g})\end{array}$ & $0.05-260$ & $0.0-250$ & $0.0-3.0$ & \\
\hline
\end{tabular}


121 The potentiometric method, ASTM D664 [28], has some challenges. While this method requires an

122 electrode, the variability of the electrode dehydration may result in mediocre reproducibility and a lack of

123 accuracy in the acidity analysis [15, 22]. Additionally, a conventional $\mathrm{pH}$ electrode is originally designed

124 to measure the $\mathrm{pH}$ in aqueous systems. Hence, the $\mathrm{pH}$ value would be different in non-aqueous systems

125 (i.e., titration solvent) due to possible effects of the non-aqueous solvent on the $\mathrm{pH}$ and reference

126 electrode, including effects on proton activity [33]. All current standard methods require

$127 \mathrm{KOH} /$ isopropanol as the titrant solution and the mixture of toluene and isopropanol as a titration solvent.

128 Thus, the measured $\mathrm{pH}$ refers to these conditions. Another challenge for using organic solvents is that

129 toxic chemical waste is generated when analyzing the TAN value by standard methods due to the titration

130 solvent. Therefore, many researchers have indicated that current standard methods are labor-intensive,

131 expensive, error-prone, and harmful to the environment $[14,16,17,23]$.

133 To improve the currently available standard methods, many research groups have modified these methods

134 to reduce the error in reproducibility. Furthermore, modified methods were quicker, simpler, cheaper,

135 more environmentally friendly, and more accurate. Some modifications from other groups are

136 summarized in Table 2-a, b for reference. An organic titrant solution was replaced by aqueous solutions

$137(\mathrm{KOH}$ in water $[4,34]$ or $\mathrm{NaOH}$ in water $[14,23,24]$. The toxic titration solvent was substituted with less

138 harmful solvents (e.g., only isopropanol [19], solely acetone [4, 34], a mixture of ethanol and water [14,

$13923,24]$, and a mixture of acetone and tert-butanol [12]). Additionally, decreasing the amount of titration

140 solvent $[4,14-16,19,23,24,34]$ and the sample weight $[15,16,34]$ were attempted by many groups.

141 Other modifications include changing the electrode filling solution [19] and introducing different

142 electrode cleaning procedures $[23,24]$ to address dehydration in the electrode. 
143 Table 2-a. Modifications of total acid number analysis of biofuels

\begin{tabular}{|c|c|c|c|c|}
\hline Modifications & Baig et al. $[15,16]$ & Aricetti et al. [14] & Tubino et al. $[23,24]$ & Gonçalves et al. [19] \\
\hline Standards & ASTM D974 & AOCS Cd 3d-63 & $\begin{array}{c}\text { ABNT-NBR } 14448 \text { [23], AOCS Cd 3d-63 } \\
\text { and ABNT-NBR } 14448 \text { [24] }\end{array}$ & ASTM D664 \\
\hline Methods & Colorimetric & Colorimetric & Potentiometric & Potentiometric \\
\hline Alkaline titrant & $\mathrm{KOH}$ & $\mathrm{NaOH}$ & $\mathrm{NaOH}$ & $\mathrm{KOH}$ \\
\hline Solvent for titrant & isopropanol & Water & Water & isopropanol \\
\hline Titrant conc. $(\mathrm{M})$ & 0.02 & 0.02 & 0.02 & 0.01 \\
\hline Titration solvent & toluene:isopropanol:water & ethanol:water & ethanol:water & isopropanol \\
\hline Volume ratio & 100:99:1 & $1: 1$ & $1: 1$ & 1 \\
\hline Solvent vol. $(\mathrm{mL})$ & 10 & 75 & 75 & 50 \\
\hline Indicator & p-naphtholbenzein & phenolphthalein & $\mathrm{n} / \mathrm{a}$ & $\mathrm{n} / \mathrm{a}$ \\
\hline Amount of indicator & 8 drops & $\mathrm{n} / \mathrm{a}$ & $\mathrm{n} / \mathrm{a}$ & $\mathrm{n} / \mathrm{a}$ \\
\hline Sample weight $(\mathrm{g})$ & 2 & 20 & 20 & $\mathrm{n} / \mathrm{a}$ \\
\hline Sample type & Distilled biodiesel, biodiesel blends & Biodiesel & Biodiesel [23], oils and fats [24] & Biodiesel \\
\hline Other modifications & a $5 \mathrm{~mL}$ burette with division of $0.02 \mathrm{~mL}$ & $\mathrm{n} / \mathrm{a}$ & $\begin{array}{l}\text { Rinsing the electrode with ethanol and } \\
\text { soaked it in water for } 1 \mathrm{~min}\end{array}$ & $\begin{array}{c}\text { Electrode filling solution } \\
(3.0 \mathrm{~mol} / \mathrm{L} \text { aqueous } \mathrm{KCl} \text { solution })\end{array}$ \\
\hline Results & $\begin{array}{l}\text { - Reduced max error (from } 42.88 \% \text { to } \\
5.92 \% \text { ); good accuracy and } \\
\text { repeatability [15] } \\
\text { - Reduced max error (from } 101 \% \text { to } \\
18 \% \text { ); repeatability decreased (from } \\
290 \% \text { to } 100 \% \text { [14] }\end{array}$ & $\begin{array}{l}\text { - Reliable, accurate, and precise TAN } \\
\text { - Same results as AOCS Cd 6d-63 with a } \\
\text { little better precision }\end{array}$ & $\begin{array}{l}\text { - Statistically equivalent results as } \\
\text { ABNT NBR } 14448 \\
\text { - Less dehydration of the electrode [23] } \\
\text { - Easier endpoints determination [24] }\end{array}$ & $\begin{array}{l}\text { - Good repeatability that was lower than } \\
\text { that of colorimetric method } \\
\text { - The difference in TAN for different } \\
\text { solvents and filling solutions was }<5 \% \\
\text { - Statistically similar results from } \\
\text { standard methods and modifications }\end{array}$ \\
\hline Advantages & $\begin{array}{l}\text { Easy, reproducible, cost-effective, } \\
\text { environmentally friendly, and time- } \\
\text { efficient }\end{array}$ & $\begin{array}{l}\text { Greener solvent, less solvent, aqueous } \\
\text { titrant, cheaper }(82 \%)\end{array}$ & $\begin{array}{l}\text { Minimizing dehydration of the electrode } \\
\text { by using aqueous solution of ethanol as } \\
\text { the solvent; quicker analysis, which } \\
\text { decreases the possibility of dehydration of } \\
\text { the electrode; less organic solvents, lower } \\
\text { cost, greener method, lower toxicity }\end{array}$ & $\begin{array}{l}\text { Less toxic and lower probability of } \\
\text { causing possible aqueous hydrolysis of } \\
\text { methyl esters }\end{array}$ \\
\hline Challenges & $\begin{array}{l}\text { Color changes at endpoint of titration of } \\
\text { dark-colored samples could not be } \\
\text { observed. }\end{array}$ & $\begin{array}{l}\text { Difficult endpoint determination as a } \\
\text { function of the yellow color of biodiesel }\end{array}$ & $\mathrm{n} / \mathrm{a}$ & $\mathrm{n} / \mathrm{a}$ \\
\hline
\end{tabular}

144 [ABNT: the Brazilian Association of Technical Standards (Associação Brasileira de Normas Técnicas)] 
Table 2-b. Modifications of total acid number analysis of biofuels (continued)

\begin{tabular}{|c|c|c|c|}
\hline Modifications & Fuhr et al. [26] & Shao et al. [34] and Oasmaa et al. [4] & Wu et al. [12] \\
\hline Standards & ASTM D664 & ASTM D664 & ASTM D664 \\
\hline Methods & Potentiometric & Potentiometric & Potentiometric \\
\hline Alkaline titrant & $\mathrm{KOH}$ & $\mathrm{KOH}$ & tetramethylammonium hydroxide (TMAH) \\
\hline Solvent for titrant & isopropanol & water & methanol and isopropanol (1:10 v.) \\
\hline Titrant conc. $(\mathrm{M})$ & $0.05,0.1,0.15(\mathrm{~N})$ & 0.1 & $0.12 \mathrm{mM}$ \\
\hline Titration solvent & toluene:isopropanol & acetone & acetone: tert-butanol \\
\hline Volume ratio & $75: 25$ & 1 & $1: 9$ \\
\hline Solvent vol. $(\mathrm{mL})$ & 125 & 50 & $\mathrm{n} / \mathrm{a}$ \\
\hline Sample weight (g) & $1-2$ & $0.1-0.5$ & $\mathrm{n} / \mathrm{a}$ \\
\hline Sample type & Heavy oils and bitumens & Bio-oil & Bio-oil \\
\hline Others & $\begin{array}{c}\text { time }<30 \text { min; pretreatment of samples }= \\
\text { heating to } 60^{\circ} \mathrm{C}\end{array}$ & Used $0.1 \mathrm{~mol} / \mathrm{L} \mathrm{HCl}$ in water as standard solution & Nonaqueous titration \\
\hline Results & $\begin{array}{l}\text { - Concentrations of titrant have no effect } \\
\text { - Pretreatment is required for viscous } \\
\text { samples } \\
\text { - More toluene in titration solvent can } \\
\text { dissolve samples } \\
\text { - Good reproducibility }\end{array}$ & $\begin{array}{l}\text { - Sample size }(0.1-0.5 \mathrm{~g}) \text { and solvent volume } \\
(50-125 \mathrm{~mL}) \text { did not have effects on TAN } \\
\text { analysis } \\
\text { - Possible recycling titration solvent (up to three } \\
\text { times) }\end{array}$ & $\begin{array}{l}\text { - Detected heavy carboxylic acids and } \\
\text { phenolics as well as strong acids } \\
\text { - Differentiated the carboxylic acids and } \\
\text { phenolic groups through a non-aqueous } \\
\text { titration potentiometric titration }\end{array}$ \\
\hline Advantages & $\begin{array}{l}\text { Suitable analysis of viscous samples } \\
\text { (perhaps this modification is applicable for } \\
\text { organic phase of bio-oil) } \\
\text { Titration without delay to avoid asphaltene } \\
\text { precipitation }\end{array}$ & Less toxic, cost saving, and shorter analysis time & $\begin{array}{l}\text { Nonaqueous titration: avoid leveling effect } \\
\text { and obtain distinguishable endpoints } \\
\text { Titration solution (acetone and tert-butanol) } \\
\text { can dissolve bio-oil }\end{array}$ \\
\hline Challenges & $\mathrm{n} / \mathrm{a}$ & $\mathrm{n} / \mathrm{a}$ & $\mathrm{n} / \mathrm{a}$ \\
\hline
\end{tabular}


149 Further steps have been made to develop new approaches to measuring acidity including a coulometric

150 analysis [17], a 3D-printed flow injection analysis [35], and a sequential injection analysis with

151 multivariate curve resolution-alternating least squares (SIA-MCR-ALS) [18]. Although these new

152 methods were developed for analyzing the acidity of plant oils [18], biodiesel [17, 18], and thermal

153 conductive oil [35], they may be applicable for analyzing the acidity of bio-oil as well.

155 Even though various modifications and new methods were recently developed for biofuels, it is important

156 to understand the meaning of TAN values using the standard methods. Moreover, as compared to

157 biodiesel, there are no in-depth studies on the TAN analysis of bio-oil, even though the TAN value has

158 been primarily used for measuring the acidity of bio-oil. Understanding the relationship between TAN

159 and the concentrations of acidic components found in bio-oil samples can help us develop methods to

160 reduce the acidity of bio-oil. It is also important to determine if other non-acidic chemical species present

161 in bio-oil (e.g., sugars, furans, ketones, aldehydes, phenolics) contribute to the TAN values.

162 Therefore, the objectives of this study were to: (1) analyze the acidity of switchgrass bio-oil in terms of

163 TAN value; (2) compare measured TAN values with theoretically calculated ones for standard solutions;

164 (3) investigate the relationship between TAN values and the concentrations of different chemicals species

165 found in bio-oil using standard solutions; (4) examine the effect of the titration solvent on the TAN

166 measurement by comparing the TAN values and titration curves obtained from the standard method with

167 results from the TAN analysis in aqueous environment and with equilibrium modeling results; and (5)

168 explore whether a variety of chemicals present in bio-oil have any influence on the TAN analysis by

169 examining the recovery of added acetic acid in aqueous bio-oil samples (recovery test) through the TAN

170 values. Because D664 [28] was previously employed for bio-oil acidity analysis, while D974

171 (colorimetric) was limited by the dark color of bio-oil as discussed above, we attempted to investigate the

172 relationship between TAN values and concentrations of different standard solutions using the D664

173 method [28]. In this study, a minor modification to the electrode cleaning procedure - the 1-minute

174 water-spray method described in Baig et al. [16] — was adopted. 


\section{Experimental}

\section{$176 \quad$ 2.1. Materials}

177 Acetic acid (analytical standard), propionic acid (analytical standard), vanillic acid ( $\geq 97.0 \%)$, syringic 178 acid ( $\geq 95 \%$ ), 4-hydroxybenzoic acid (HBA, $\geq 99 \%)$, 5-(hydroxymethyl)furfural (HMF, $\geq 99 \%)$, phenol ( $\geq$ $17999.5 \%)$, anhydrous 2-propanol (99.5\%) and toluene ( $\geq 99.5 \%)$ were purchased from Sigma-Aldrich

180 (Milwaukee, WI). A titrant solution, $0.1 \mathrm{~mol} / \mathrm{L} \mathrm{KOH}$ in 2-propanol was purchased from Fisher Scientific.

181 Switchgrass bio-oil was produced via intermediate pyrolysis with a semi pilot-scaled auger pyrolysis

182 system (Proton Power, Inc., Lenoir City, TN, USA) at the University of Tennessee (UT) Center for

183 Renewable Carbon. More details on the production of bio-oil are available elsewhere $[5,8,36]$.

184 Switchgrass bio-oil had $\mathrm{pH}$ of 2.5 .

2.2. Methods

\subsubsection{Bio-oil Analysis}

188 The chemical composition of crude, aqueous bio-oil, and organic bio-oil (Table 3) was analyzed by gas 189 chromatography with flame ionization detector (GC-FID) and high-performance liquid chromatography 190 (HPLC). The methods involved in analyzing the chemical composition of bio-oil are found in Ren et al. 191 [5, 37]. Briefly, 2(5H)-furanone, 1-hydroxy-2-butanone, 1,3-propanediol, 3-methyl-1,2-

192 cyclopentanedione, guaiacol, creosol, 2,6-dimethoxyphenol, and 3-ethylphenol were quantified using GC193 FID with an HP-5 column $(30 \mathrm{~m} \times 0.32 \mathrm{~mm}, 0.25 \mu \mathrm{m}$ film thickness $)[5,37]$. The detailed settings for 194 GC-FID are available in the literature [5, 37]. The identification of compounds was performed by 195 comparing their mass spectra with those from the National Institute of Standards and Technology (NIST) 196 mass spectral data library. Acetic acid, propionic acid, levoglucosan, hydroxymethylfurfural, furfural, 197 phenol, and 1,2-benzendiol were analyzed using an HPLC, Jasco 2000Plus (Jasco Analytical Instruments, 198 Easton, MD) with an MD-2018 plus photodiode array detector, an RI-2031 Plus intelligent refractive 199 index detector, and an AS-2055 plus autosampler. The chemical analysis using HPLC was performed at $20050^{\circ} \mathrm{C}$ with a Bio-Rad column HPX-87H $(300 \times 8 \mathrm{~mm})$. The injected sample volume was $20 \mu \mathrm{L}$. Sulfuric 
201 acid $(5 \mathrm{mM})$ in deionized water was used as the mobile phase with a flow rate of $0.6 \mathrm{~mL} / \mathrm{min}$. The

202 compounds were quantified using external standards in both the HPLC and GC-FID analyses. For water

203 content measurements, a Schott TitroLine Karl Fischer volumetric titrator was used according to the

204 ASTM D4377 (2011) method [38].

205

\section{2.2.2. Total Acid Number Analysis}

207 For the TAN analysis, the ASTM D664 method [28] was followed except for the cleaning procedure. In 208 brief, the titration solvent was prepared using toluene, anhydrous 2-propanol, and deionized water 209 (100:99:1 v.). It should be mentioned here that one of the ASTM D664 modifications that have been 210 suggested for biodiesel does not include toluene as one of the titration solvents. For the case of bio-oil, 211 however, we did not follow that modification because, in contrast to biodiesel, bio-oil includes organic 212 components that are not soluble in the 2-propanol/water mixture. For the titrant solution, a concentration 213 of $0.1 \mathrm{~mol} / \mathrm{L} \mathrm{KOH}$ in 2-propanol was used as received from Fisher Scientific. The volume of titration 214 solvent used was $125 \mathrm{~mL}$. Sample amounts varied depending on the range of TAN values according to 215 ASTM D664-11a [28]. The modified electrode cleaning procedure (spraying water for $1 \mathrm{~min}$ ) was 216 adapted from Baig et al. [16]. Samples were titrated to $\mathrm{pH} 11$ [5], and the TAN values were calculated by

217 following ASTM D664. Acetic acid, propionic acid, HMF, and phenol solutions were prepared in 218 deionized water with concentrations of 2, 4, and $6 \mathrm{wt} \%$. Sample analysis was preformed in triplicate.

219 Solutions of HBA and vanillic acid were prepared in 2-propanol due to its limited solubility in water and 220 higher solubility in 2-propanol [39]. Due to limited solubility of syringic acid in water or 2-propanol, 221 syringic acid solution $(0.6 \mathrm{wt} \%)$ was prepared in the titration solvent.

\subsubsection{Equilibrium MINEQL+ Modeling and Aqueous Titration}

224 The TAN analysis of acetic acid (2 wt $\%)$ was modeled using a solution equilibrium software called

225 MINEQL+ for a closed system (with respect to air). The following chemical reactions were 226 considered in modeling the TAN analysis of acetic acid ( $2 \mathrm{wt} \%)$. The equilibrium constants, $\mathrm{K}$ 
values, of these reactions were provided by the MINEQL+ library. The conditions of the

228 MINEQL+ modeling are: aqueous system, closed to the atmosphere (i.e., no carbonate species

229 considered), and room temperature $\left(25^{\circ} \mathrm{C}\right)$. water as titration solvent and $0.1 \mathrm{~mol} / \mathrm{L} \mathrm{KOH}$ solution in water as titrant solution.

\subsubsection{Bio-oil Recovery Test}

236 Crude bio-oil obtained from UT was centrifuged at $3000 \mathrm{rpm}$ (1673 g) for 30 minutes using Beckman

237 Coulter Avanti J-E centrifuge with a JLA 10.500 rotor to separate the aqueous and organic components of

238 bio-oil. The chemical compositions of aqueous bio-oil (AqBO) and organic bio-oil (OrgBO) were

239 analyzed. Due to the heterogeneity of crude bio-oil and organic bio-oil, AqBO was used in the recovery

240 test for consistency. AqBO (9 g) was mixed with $1 \mathrm{~g}$ of acetic acid solutions (20, 40, and $60 \mathrm{wt} \%$ in

241 deionized water) to yield an overall 2, 4, and $6 \mathrm{wt} \%$ of acetic acid, respectively. The TAN values of

242 acetic-acid-added AqBO samples were analyzed in triplicate. Prepared samples were also analyzed using

243 HPLC as described in Section 2.2.5.

244

\subsubsection{High-Performance Liquid Chromatography (HPLC) Analysis for Bio-oil Recovery Test}

246 Agilent 1100 was used as the HPLC system. A BioRad Aminex HPX-87H column and a refractive index

247 detector were incorporated into this system. The mobile phase of the HPLC was $5 \mathrm{mM}$ sulfuric acid with

248 a flow rate of $0.6 \mathrm{~mL} / \mathrm{min}$. Standard solutions were prepared with the mobile phase, and bio-oil samples

249 were diluted 1000 times with the mobile phase. A volume of $20 \mu \mathrm{L}$ was injected, and each sample was 250 analyzed for one hour. 


\section{Results and Discussion}

\subsection{Chemical Composition and TAN Analysis of Switchgrass Bio-oil}

254 The chemical compositions of switchgrass crude bio-oil, aqueous bio-oil, and organic bio-oil obtained

255 from GC-FID and HPLC analyses are presented in Table 3. When the heterogeneous crude bio-oil is

256 centrifuged, there were two different phases: aqueous bio-oil (supernatant) and organic bio-oil

257 (precipitate). Aqueous bio-oil contains mostly water, levoglucosan, acetic acid, and propionic acid.

258 Organic bio-oil contains less water but more furfural and phenolics than aqueous bio-oil. More than 70

259 wt \% of organic bio-oil was not quantified by GC-FID and HPLC analyses. The TAN values of crude bio-

260 oil and aqueous bio-oil were found as $109.7 \pm 4.3$ and $138.6 \pm 14.7 \mathrm{mgKOH} / \mathrm{g}$, respectively.

Table 3. The chemical compositions of crude bio-oil, aqueous (centrifuged) bio-oil, and organic bio-oil.

\begin{tabular}{llll}
\hline & Crude Bio-oil & Aqueous Bio-oil & Organic Bio-oil \\
\hline Water (weight\%) & 43.3 & 43.65 & 15.18 \\
\hline Levoglucosan & 9.09 & 9.19 & 0.72 \\
Acetic acid & 7.71 & 8.06 & 6.16 \\
Propionic acid & 3.42 & 3.57 & 0.00 \\
1-Hydroxy-2-butanone & 1.37 & 1.08 & 0.86 \\
1,3-Propanediol & 0.29 & 0.07 & 0.06 \\
HMF & 0.59 & 0.58 & 0.19 \\
Furfural & 1.38 & 0.40 & 1.35 \\
2(5H)-Furanone & 0.38 & 0.41 & 0.26 \\
3-Methyl-1,2-cyclopentanedione & 0.25 & 0.17 & 0.25 \\
1,2-Benzenediol & 0.59 & 0.42 & 0.61 \\
Phenol & 0.26 & 0.12 & 0.31 \\
Guaiacol & 0.11 & 0.13 & 0.29 \\
3-Ethylphenol & 0.38 & 0.15 & 0.74 \\
2-Methyl-4-methylphenol & 0.42 & 0.24 & 0.47 \\
2,6-Dimethoxyphenol & 0.13 & 0.11 & 0.33 \\
Quantified (wt\%) & 69.67 & 68.34 & 27.78 \\
Non-quantified (wt\%) & 30.33 & 31.66 & 72.22 \\
\hline
\end{tabular}

265 The relationship between measured TAN values of acetic acid and propionic acid solutions (2, 4, $6 \mathrm{wt} \%)$

266 and theoretical TAN values obtained from Equation 1 are presented in Figure 1. The mean of the 
267 measured TAN values, theoretical TAN values, and their repeatability are found in Table 4. According to 268 ASTM [28], the definition of repeatability calculated from Equation 2-a [15, 28, 34, 40] is given as 269 follows: "the difference between successive test results obtained by the same operator with the same 270 apparatus under constant operating conditions on identical test material would in the long run, in the 271 normal and correct operation of the test method, exceed the following values only in one case in twenty."

272 Since the titration curves of the manual TAN analyses did not have defined inflection points, the

273 acceptable repeatability for the manual titration mode is $5 \%$ of the mean based on the standard method 274 [28]. Thus, most of the data were within the acceptable repeatability $(<5 \%)$ as shown in Table 4, while 275 only one measurement exceeded the 5\% limit.

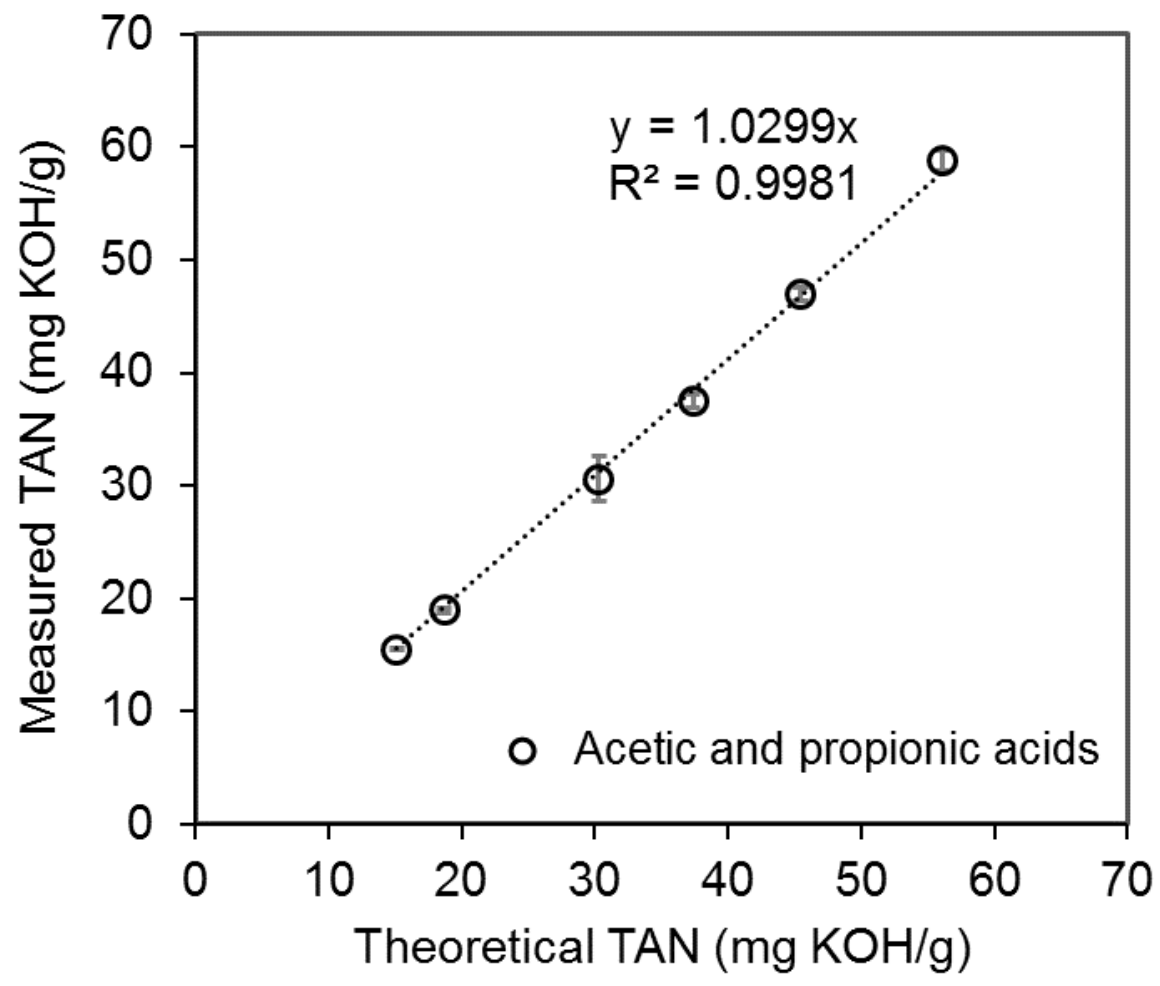

277 Figure 1. Relationship between measured TAN values of acetic acid and propionic acid solutions (2, 4, 6 $278 \mathrm{wt} \%$ ) and their theoretical TAN values obtained from Equation (1). 
281 where TAN is the total acid number $(\mathrm{mg} \mathrm{KOH} / \mathrm{g}$ ) and $\mathrm{MW}$ is the molecular weight in $\mathrm{g} / \mathrm{mol}(\mathrm{MW}$ of

282 KOH: $56.1056 \mathrm{~g} / \mathrm{mol})$.

283 Repeatability $(\%)=[(2.77 \times \mathrm{SD}) /(n \times$ mean TAN $)] \times 100 \% \quad(\mathbf{2}-\mathbf{a})$

284 Error $(\%)=($ mean of measured TAN - theoretical TAN $) /($ theoretical TAN $) \times 100 \%$

285 where $n$ is the number of operators involved in the analysis ( 1 in this case), and SD is the standard

286 deviation.

287

Table 4. Theoretical and measured TAN values of acetic and propionic acids standard solutions.

289

\begin{tabular}{ccccccc}
\hline Chemicals & Concentration & $\begin{array}{c}\text { Theoretical } \\
\text { TAN } \\
\text { wt\% }\end{array}$ & mol/L & $\begin{array}{c}\text { Mean } \\
\text { measured } \\
\text { TAN } \\
\text { (mgKOH/g) }\end{array}$ & $\begin{array}{c}\text { Standard } \\
\text { deviation } \\
(\mathrm{mgKOH} / \mathrm{g})\end{array}$ & $\begin{array}{c}\text { Repeatability } \\
(\%)\end{array}$ \\
\hline \multirow{2}{*}{ Acetic acid } & 2 & 0.33 & 18.69 & 18.96 & 0.24 & 3.5 \\
& 6 & 0.67 & 37.37 & 37.46 & 0.63 & 4.6 \\
\hline Propionic & 2 & 0.27 & 15.15 & 15.47 & 0.08 & 1.5 \\
acid & 4 & 0.54 & 30.30 & 30.55 & 2.00 & 18.2 \\
\hline
\end{tabular}

\section{3.3. TAN Analysis of Standard Solutions}

292 Oasmaa et al. [4] found that there were different linear relationships between TAN values and the

293 concentrations of acetic acid and formic acid standard solutions (wt\%). The reason for the different linear

294 relationships, however, was not discussed. When the same data are replotted against molar concentrations,

295 as shown in Figure 2, it is clear that both formic and acetic acids actually have the same linear

296 relationship of TAN vs molar concentrations. The combined data resulted in a slope of 58.494, which is

297 very close to the combined slope (58.059) discussed later in this paper. 


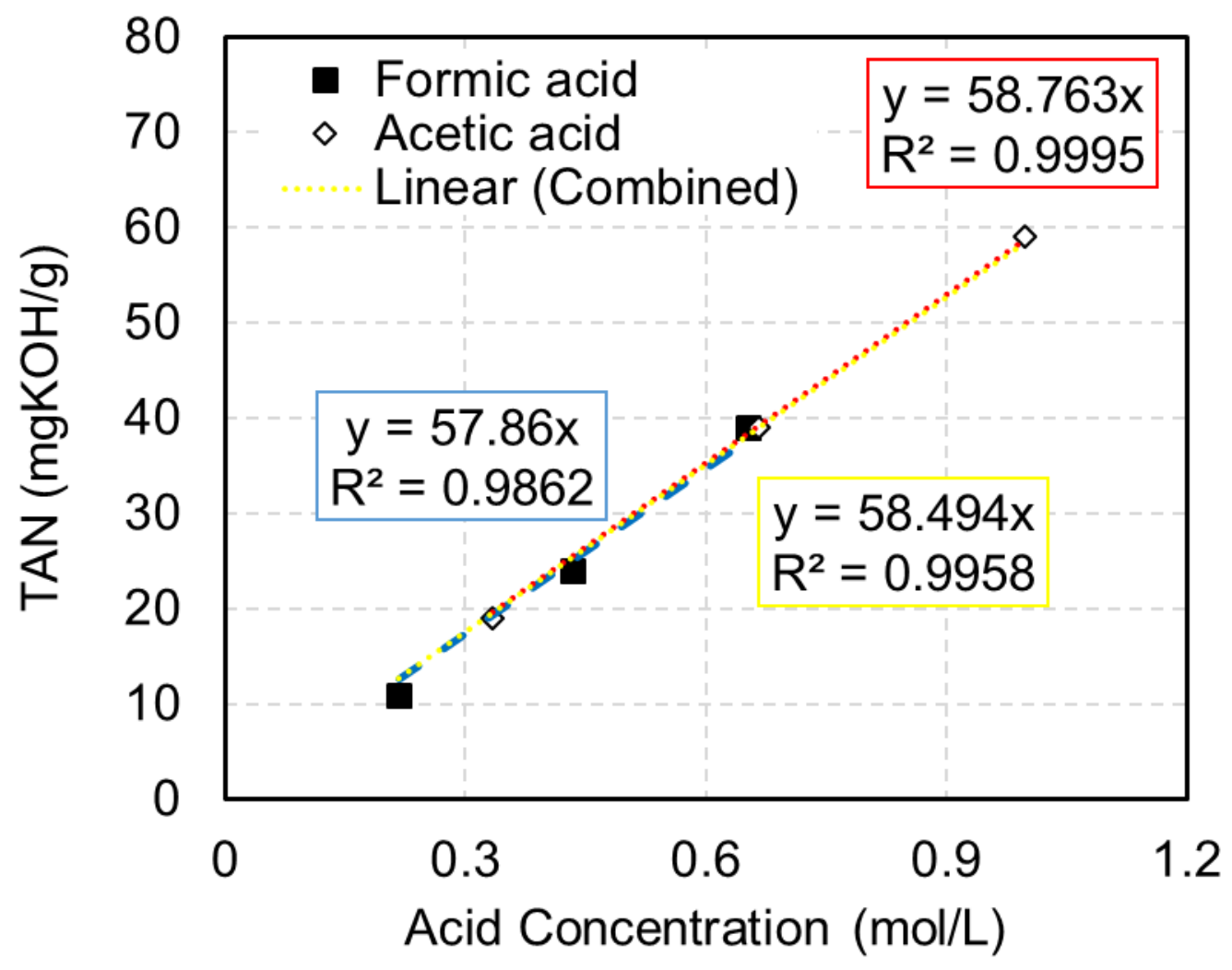

299

Figure 2. The same relationship is found when the TAN value is plotted vs molar concentrations of formic and acetic acid (data obtained from Figure 5 in Oasmaa et al. [4]).

To further investigate the relationship between the TAN value and concentrations of various chemicals, the TAN analysis of standard solutions was performed for different concentrations (2, 4, and $6 \mathrm{wt} \%)$. All standard solutions except hydroxybenzoic, vanillic, and syringic acids were prepared in deionized water. Solutions of HBA and vanillic acid were prepared in 2-propanol due to its limited solubility in water [39]. Preparing HBA and vanillic acid solutions in 2-propanol should not affect the TAN analysis because the

307 titration solvent $(125 \mathrm{~mL})$ used contains 2-propanol (toluene: 2-propanol: water =100:99:1 v.) at a 308 relatively high concentration.

310 The measured TAN values are plotted vs weight percent in Figure 3. As the concentration of the acidic 311 solutions increased, the TAN values also increased. Unlike the acidic solutions, the phenol and HMF 
312 solutions did not influence the TAN measurements despite that phenols are more acidic than alcohols and

313 may form phenoxide ions by reacting with hydroxide ions [4]. This is due to the high $\mathrm{pK}_{\mathrm{a}}$ value (10.02) of

314 the phenol, as well as the effect of the nonaqueous solvent. The low sensitivity of the standard method

315 (ASTM D664) towards weak acids like phenol may be due to a suboptimal acidity of 2-propanol as Wu et

316 al. [12] pointed out.

318 The linear trendline of acetic acid, which has the lowest molecular weight, had the highest slope, while

319 the vanillic acid with the highest molecular weight had the lowest slope. The relationship between the

320 TAN value and weight percent of standard solutions shown in Figure 3 can be described by Equations

321 (3-a, b, c). As shown in Equation (1-c), the slope of each line in Figure 3 depends on the molecular

322 weight of the sample.

323

324 Weight percent

325

$T A N=[$ slope $] \times[w t \%]$

(3-a)

$326 \operatorname{TAN}(\mathrm{mgKOH} / \mathrm{g})=\frac{\text { MWof KOH }(\mathrm{g} / \mathrm{mol})}{\text { MWof Sample }(\mathrm{g} / \mathrm{mol})} \times 1000\left(\frac{\mathrm{mg}}{\mathrm{g}}\right) \times \frac{\operatorname{Sample}(\mathrm{g})}{\operatorname{Total}(\mathrm{g})} \% \times \alpha$

$327 \quad[$ slope $]=\frac{\text { MWof } \mathrm{KOH}(\mathrm{g} / \mathrm{mol})}{\text { MWof Sample }(\mathrm{g} / \mathrm{mol})} \times 1000\left(\frac{\mathrm{mg}}{\mathrm{g}}\right) \times \alpha$

328 where $[w t \%]=\frac{\operatorname{Sample}(g)}{\operatorname{Total}(g)} \%$, where $\operatorname{Total}(g)=\operatorname{Sample}(g)+\operatorname{Solvent}(g)$

Molar concentration

$331 \quad T A N=[$ slope $] \times[M]$

332

$$
\operatorname{TAN}(m g K O H / g)=\frac{\operatorname{Sample}(g)}{\operatorname{Total}(L)} \times \frac{1}{M W o f \operatorname{Sample}(g / m o l)} \times \frac{\operatorname{Total}(L)}{\operatorname{Total}(g)} \times \operatorname{MWof} \operatorname{KOH}(\mathrm{g} / \mathrm{mol}) \times 10001\left(\frac{m g}{g}\right) \times \alpha
$$

333

$$
\operatorname{TAN}\left(\frac{m g K O H}{g}\right)=\frac{\operatorname{Total}(L)}{\operatorname{Total}(g)} \times M \operatorname{Wof} \mathrm{KOH}(\mathrm{g} / \mathrm{mol}) \times 1000\left(\frac{m g}{g}\right) \times \alpha \times[M]
$$


336 where $[\mathrm{M}]:$ molar concentration $=\operatorname{mol} / L=\frac{\operatorname{Sample}(\mathrm{g})}{\operatorname{Total}(L)} \times \frac{1}{M W o f \operatorname{Sample}(\mathrm{g} / \mathrm{mol})}$

$$
\rho_{\text {Total }}=\frac{\operatorname{Total}(g)}{\operatorname{Total}(L)}
$$

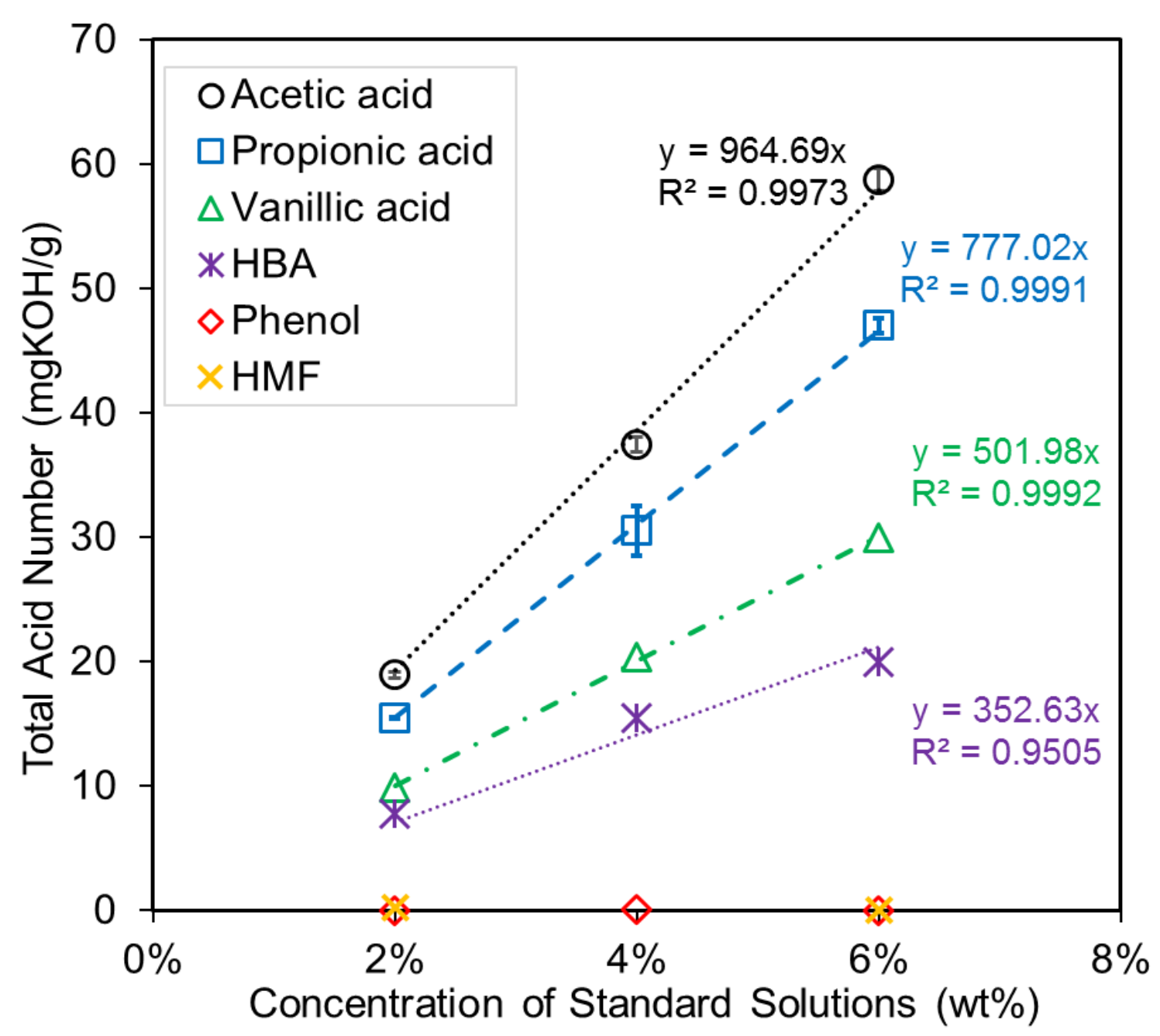

340 Figure 3. Different linear relationships between TAN values and weight percent concentrations of

341 standard solutions of acetic acid, propionic acid, vanillic acid, and phenol. 
342 Since the slopes of different linear relationships are inversely related to the molecular weight, the same 343 data points were plotted with the x-axis as molar concentration as shown in Figure 4. Acetic, propionic, 344 and hydroxybenzoic acids showed the same linear relationship; however, vanillic acid showed a different 345 linear relationship. The slope of vanillic acid in Figure 4 is approximately two times the slope of acetic, 346 propionic, and hydroxybenzoic acids. The relationship between TAN value and molar concentrations of 347 standard solutions from Figure 4 is described by Equations (4-a through 4-e). The slope of each line in

348 Figure 4 is inversely related to the density of the standard solution. The different concentration standard 349 solutions that were analyzed in this research were assumed to have similar density. However, at higher 350 concentrations, the density of solutions may change causing also a change in the slope of the line.

352 The slope of linear relationships is also related to the alpha factor. The alpha factor $(\alpha)$ in Equations (3)

353 and (4) is the number of functional groups that contribute to the TAN value or the number of protons that 354 can be removed during the TAN analysis. For instance, if a compound had more than one functional 355 group that could react with $\mathrm{KOH}$, consuming $\mathrm{KOH}$ with multiple functional groups would lead to a 356 stronger effect on the TAN value as compared to compounds with only one acidic functional group. Even 357 though vanillic acid has one carboxylic acid group, its slope, which is double the slope of other 358 monoprotic acids, indicates that two protons were removed during the TAN analysis. This is because 359 vanillic acid loses two protons and acts as diprotic acid during the TAN analysis (titration to $\mathrm{pH} 11$ ) in the 360 titration solvent system. Therefore, the alpha factor for formic, acetic, propionic, and hydroxybenzoic 361 acids is 1 , while the alpha factor for vanillic acid is found to be 2 .

363 The results in Figure 4 are summarized in Table 5 with chemical structures and $\mathrm{pK}_{\mathrm{a}}$ values. As expected, 364 HMF that has $\mathrm{pK}_{\mathrm{a}}$ value of 12.82 with the slope of 0 did not contribute to the TAN values. Because the 365 samples were titrated to $\mathrm{pH} 11$ during TAN analysis, hydrogen atoms with $\mathrm{pK}_{\mathrm{a}}$ values less than 11 were 366 expected to be titrated. The $\mathrm{pK}_{\mathrm{a}}$ of the hydrogen in phenol was less than 11; however, phenol did not 367 contribute to the TAN value. As discussed in the following section (3.4), the reason for this behavior 
could be that the actual acid-base constants in the TAN standard titration solvent are different from $\mathrm{pK}_{\mathrm{a}}$

369 values reported for the aqueous system. Acetic, propionic, and hydroxybenzoic acids had a slope of

37058.059 , which is close to the molecular weight of $\mathrm{KOH}$. HBA has two hydrogens that have $\mathrm{pK}_{\mathrm{a}}$ values of

3714.38 and 9.67. Based on the slope of the linear relationship, only the hydrogen in the carboxylic group

372 contributed to the TAN value and was removed during the TAN analysis. Vanillic acid has a very similar

373 chemical structure as HBA except for the presence of a methoxy group. The slope of the linear

374 relationship (Figure 4) for vanillic acid was 114, approximately double that for other acids. The slope of

375 vanillic acid indicates that the two protons were removed during the TAN analysis (one from its

376 carboxylic group and the other from its hydroxyl group). Perhaps the presence of the methoxy group

377 helped the hydrogen in the hydroxyl group to be removed in the titration solvent - the mixture of toluene,

378 2-propanol, and water. It is noteworthy that the $\mathrm{pK}_{\mathrm{a}}$ values presented in Table 5 are based on aqueous

379 systems. For consistency, the $\mathrm{pK}_{\mathrm{a}}$ values of chemicals were obtained from chemical calculations from

380 Chemicalize provided by ChemAxon [41] except the $\mathrm{pK}_{\mathrm{a}}$ value of $\mathrm{HMF}$, which was obtained from

381 another source [42]. In the titration solvent system (toluene, isopropanol, and water - 100:99:1 v.), the

$382 \mathrm{pK}_{\mathrm{a}}$ values are certainly changing due to interactions between the titration solvent molecules and the

383 various chemical species. Further investigations, which are not within the scope of this research, are

384 needed to fully understand those interactions.

386 The data points for the TAN values of the acetic, propionic, and hydroxybenzoic acids were combined in

387 Figure 4, and these data are well represented by a solid line, as shown on the graph. The combined slope

388 for acetic, propionic, hydroxybenzoic acids is 58.059, which is close to the molecular weight of $\mathrm{KOH}$

389 (56.1056 g/mol). Thus, if a sample contains formic, acetic, propionic, and hydroxybenzoic acids, then the

390 TAN value of the sample can be converted to the molar concentration of total acids using the following

391 relationship, where $\mathrm{M}$ is the concentration in $\mathrm{mol} / \mathrm{L}$.

$392[\mathrm{M}$ of total acids $]=[\mathrm{TAN}(\mathrm{mg} \mathrm{KOH} / \mathrm{g})] /\left[58.059\left(\mathrm{mg} \mathrm{KOH} \mathrm{M}^{-1} \mathrm{~g}^{-1}\right)\right]$ 
393 If a sample such as bio-oil, however, contains acidic components such as vanillic acid, which have a 394 stronger contribution to the TAN value than monoprotic acids, Equation (5) cannot be used to convert 395 the TAN measurement to the molar concentration of total acidic components.

397 The TAN analysis of syringic acid solutions was also attempted. Due to limited solubility of syringic acid 398 in water and isopropanol, the TAN titration solvent (toluene: isopropanol: water = 100: 99: $1 \mathrm{v}$.) was used 399 to prepare the syringic acid solution. The maximum concentration that we were able to prepare was 0.6 $400 \mathrm{wt} \%$ of syringic acid in the titration solvent. Unfortunately, the TAN value of $0.6 \mathrm{wt} \%$ of syringic acid 401 could not be obtained because, during the TAN analysis of syringic acid, the $\mathrm{pH}$ value of the titration 402 system could not reach 11 , which is the end-titration $\mathrm{pH}$ according to the standard method. Instead, the 403 maximum $\mathrm{pH}$ reached was 9.5. After reaching $\mathrm{pH}$ 9.5, precipitation of solids occurred, and the $\mathrm{pH}$ value 404 dropped significantly. This means that, when a sample contains syringic acid, even at low concentrations, 405 a strong contribution to the TAN value can be expected because syringic acid in the sample will consume 406 the $\mathrm{KOH}$ solution during titration; therefore, it would take more $\mathrm{KOH}$ solution for the system to reach $\mathrm{pH}$ 407 11, leading to a higher TAN value than that obtained in the absence of syringic acid. 


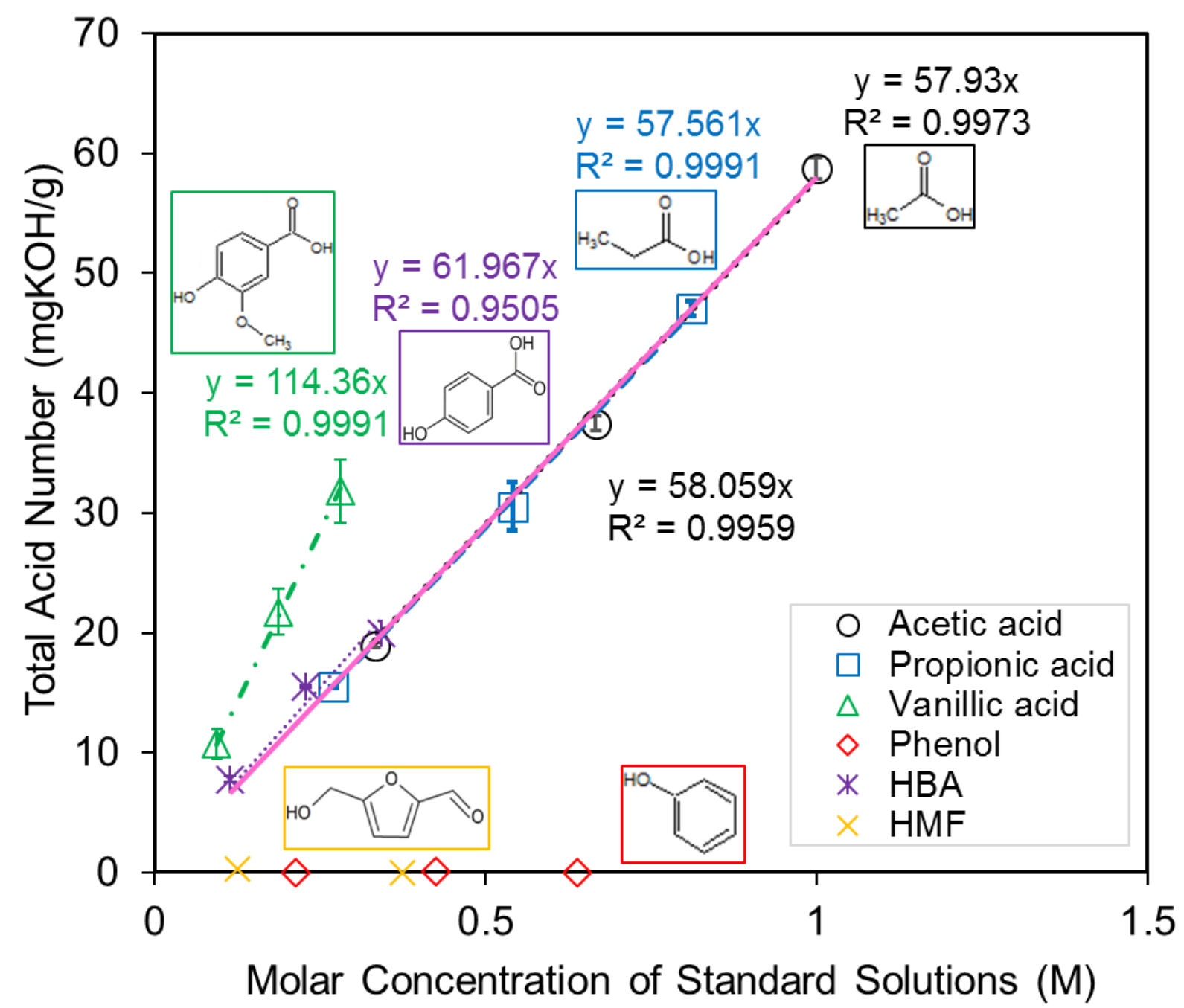

Figure 4. Relationship between TAN and molar concentrations of various bio-oil components. The TAN

411 value of acetic, propionic, and hydroxybenzoic acids shows the same linear relationship vs. molar

412 concentrations, represented by a solid trendline. The TAN vs. molar concentration line for vanillic acid

413 shows a higher slope because of the release of 2 protons during titration to $\mathrm{pH} 11$. Phenol and HMF show

414 zero contribution to the TAN value. 
415 Table 5. Slopes of the linear relationships between TAN value and the molar concentration of various

416 chemicals found in bio-oil with their chemical structure and $\mathrm{pK}_{\mathrm{a}}$ values obtained from the literature for

417 HMF [42] and online chemical calculations from Chemicalize provided by ChemAxon [41] for other

418 chemicals.

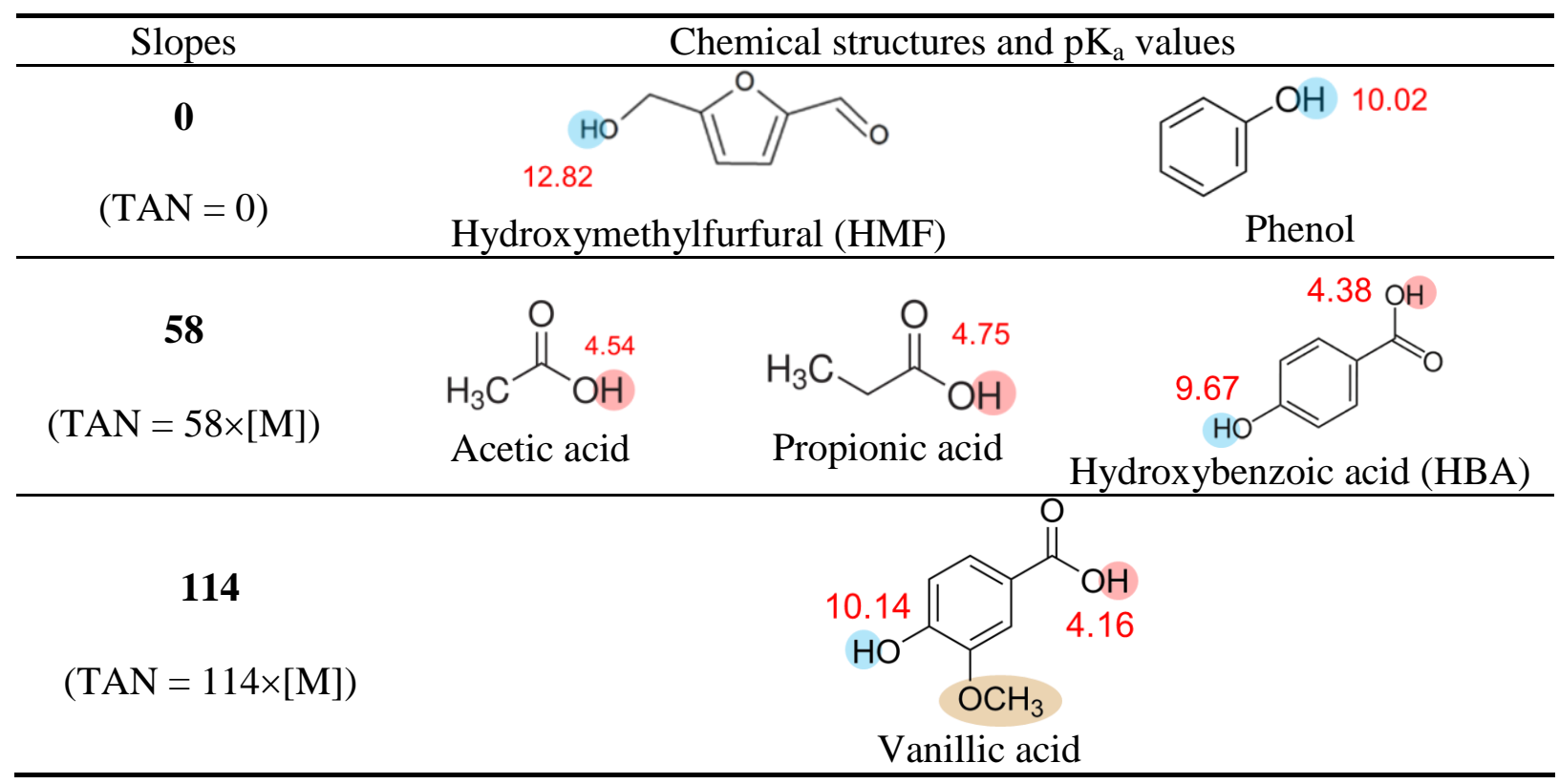

$[\mathrm{M}]$ is the molar concentration in $\mathrm{mol} / \mathrm{L}$.

422 To investigate the effect of the titration solvent (i.e., the mixture of toluene, 2-propanol, and water),

423 we employed MINEQL+, a solution equilibrium software, to model the TAN analysis. The

424 MINEQL+ software is designed to model aqueous systems. Results from the MINEQL+ modeling

425 are presented in Figure 5, where the molar concentration of potassium ions needed for the system

426 to reach $\mathrm{pH} 11$ is estimated at $3.67 \times 10^{-3} \mathrm{~mol} / \mathrm{L}$. This amount can be converted to TAN value using

427 the following equation based on the assumption that $1 \mathrm{~g}$ of sample is titrated in $125 \mathrm{~mL}$ of water

428 [i.e., a total volume of $0.126 \mathrm{~L}(0.125 \mathrm{~L}$ of water and $\sim 0.001 \mathrm{~L}$ of sample) was used in the

429 calculation] as described in Equations (6-a, b). Thus, the TAN value obtained from MINEQL+ 
modeling is $25.45 \mathrm{mgKOH} / \mathrm{g}$ [Equation (6-b)], which is different from the actual TAN value obtained from the TAN analysis using the ASTM D664 method (18.96 mgKOH/g).

Since the TAN values from the ASTM method and the MINEQL+ modeling were different, the

434 TAN analysis in an aqueous system was performed using $2 \mathrm{wt} \%$ of acetic acid, water as the titration

435 solvent, and $0.1 \mathrm{~mol} / \mathrm{L} \mathrm{KOH}$ solution in water. The experimental TAN analysis in the aqueous

436 system is also presented in Figure 5. The amount of $\mathrm{KOH}$ solution added was measured during this

437 analysis, and for comparison with the results from MINEQL+, the volume of KOH solution added

438 was converted to molar concentration of $\mathrm{KOH}$. From Figure 5, the amount of $\mathrm{KOH}$ required to

439 titrate the system to $\mathrm{pH} 11$ is estimated at $3.63 \times 10^{-3} \mathrm{~mol} / \mathrm{L}$. Similarly to Equation (6-b), this

440 concentration $\left(3.63 \times 10^{-3} \mathrm{~mol} / \mathrm{L}\right)$ can be converted to TAN value as shown in Equation (6-c). $=[$ Concentration of $\mathrm{KOH},(\mathrm{mol} / \mathrm{L})] \times[$ molecular weight of $\mathrm{KOH},(\mathrm{g} / \mathrm{ml})] \times[$ unit conversion, $(\mathrm{mg} / \mathrm{g})] \times[$ total volume of the system, $(\mathrm{L})] /[$ weight of a sample, $(\mathrm{g})](\mathbf{6}-\mathbf{a})$

Hence, the TAN value obtained from the TAN analysis in the aqueous system is $25.66 \mathrm{mgKOH} / \mathrm{g}$, which is very close to the TAN value from MINEQL+ $(25.45 \mathrm{mgKOH} / \mathrm{g})$ but different from the

450 TAN analysis using the ASTM method. The TAN analysis of acetic acid (2 wt $\%)$ using the ASTM

451 D664 standard method is shown in Figure 5. To compare with the results from MINEQL+ and the 452 experimental aqueous TAN analysis, the data were plotted as $\mathrm{pH}$ vs. molar concentrations of $\mathrm{KOH}$ 453 added. Unlike the titration curves from MINEQL+ modeling and aqueous TAN analysis, the 454 starting $\mathrm{pH}$ value is around 6.4, which is higher than the MINEQL+ model and the aqueous TAN 
455 analysis ( pH 3.8). The TAN value from this analysis is $18.96 \mathrm{mgKOH} / \mathrm{g}$, which is lower than the

456 results from the model and aqueous system.

458 The results from MINEQL+, aqueous TAN analysis, and standard TAN analysis are summarized in

459 Table 6. The MINEQL+ modeling results agree well with the experimental TAN analysis data for

460 the aqueous system; however, these TAN values were significantly higher than the TAN value

461 obtained from the ASTM D664 standard method. The initial pH value in the standard titration

462 solvent was higher than those in aqueous systems. Different titration curves between aqueous and

463 titration solvent systems also represent the different $\mathrm{pK}_{\mathrm{a}}$ values in these systems. These differences,

464 as well as different TAN values, indicate that there may be different reactions and activities among

465 the solvent molecules, sample molecules (e.g., acetic acid), and the titrant (i.e., KOH). As

466 mentioned earlier, $\mathrm{pK}_{\mathrm{a}}$ values (i.e., the logarithm of acid dissociation constants) that represent

467 dissociation in acid-base reactions, are reported for the aqueous system. Therefore, the TAN values

468 obtain from the MINEQL+ modeling, which is based on the $\mathrm{pK}_{\mathrm{a}}$ values, are comparable with results

469 from aqueous TAN analysis. Since the ASTM method uses a mixture of toluene, isopropanol, and

470 water as a titration solvent, the dissociations of compounds in terms of acid-base reactions are

471 expected to be different from those occurring in the aqueous system. In short, the $\mathrm{pK}_{\mathrm{a}}$ values of

472 compounds during the ASTM standard TAN analysis should be different from the known $\mathrm{pK}_{\mathrm{a}}$

473 values for the aqueous system. In order to fully understand these differences, the reactions or

474 activities among the sample and titration solvent molecules need to be further investigated.

475 


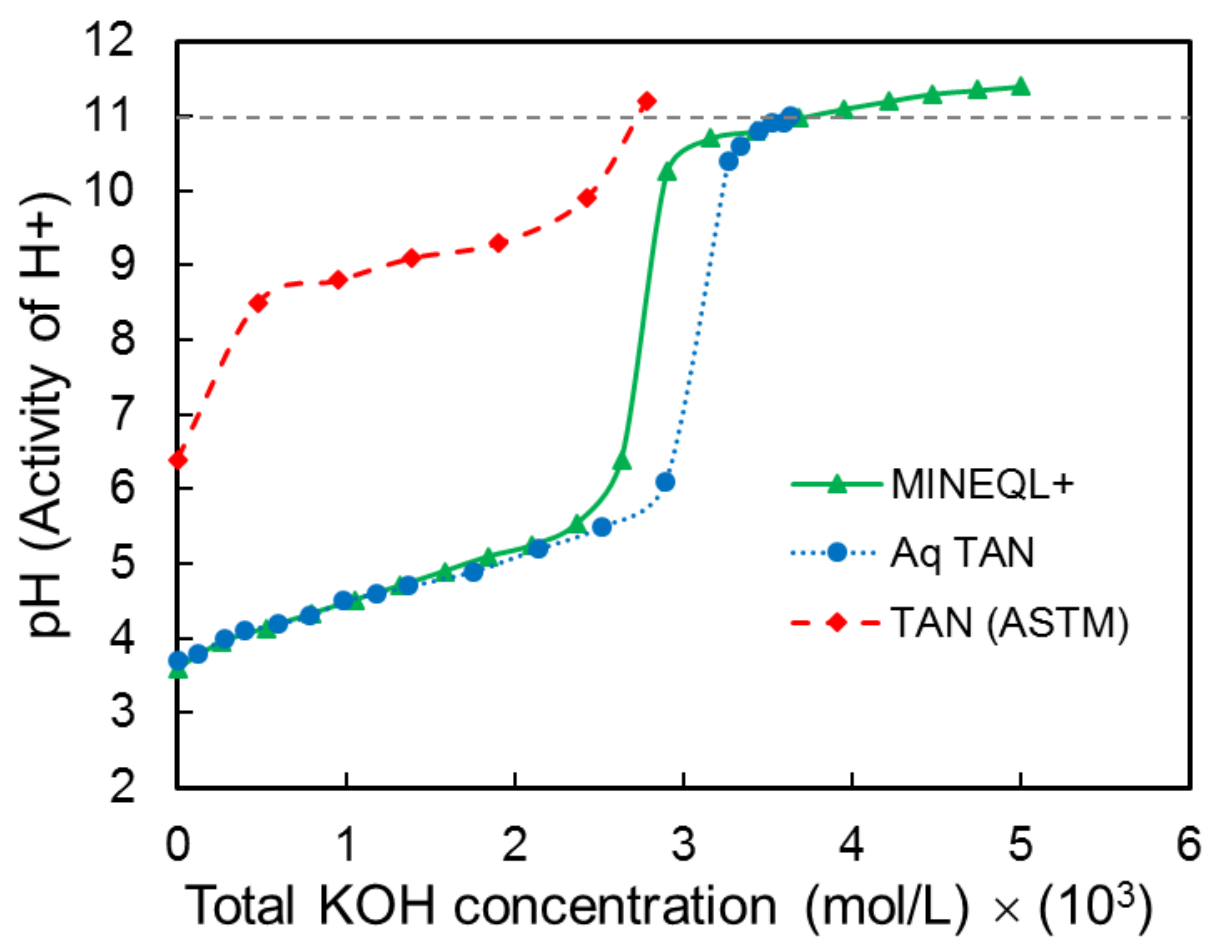

476

Figure 5. Titration curves of acetic acid (2 wt $\%)$ solution from MINEQL+ modeling, aqueous titration, and standard titration (ASTM D664)

Table 6. Summary of TAN values from MINEQL+ modeling and experimental TAN analysis in aqueous system and the titration solvent from ATSM D664

\begin{tabular}{llll}
\hline & MINEQL+ & Aqueous System & ASTM TAN Analysis \\
\hline Sample (Conc.) & Acetic acid $(2 \mathrm{wt} \%)$ & Acetic acid $(2 \mathrm{wt} \%)$ & Acetic acid $(2 \mathrm{wt} \%)$ \\
Titration Solvent & Water & Water & $\begin{array}{l}\text { Isopropanol: toluene: } \\
\text { water }(100: 99: 1 \mathrm{v} .)\end{array}$ \\
TAN $(\mathrm{mgKOH} / \mathrm{g})$ & 25.45 & 25.66 & 18.96 \\
{$[\mathrm{~K}+](\mathrm{mol} / \mathrm{L})$} & $3.67 \times 10^{-3}$ & $3.63 \times 10^{-3}$ & $2.68 \times 10^{-3}$ \\
\hline
\end{tabular}

\subsection{Recovery Test on Acetic Acid in Bio-oil Samples}

Here, to verify whether the addition of acetic acid can be detected by TAN analysis and whether the various chemical species in switchgrass intermediate-pyrolysis bio-oil affect the TAN analysis, a recovery test was performed. Previously, a recovery test with biodiesel samples was performed by a coulometric 
titration method [17]. In this study, a similar recovery test, which involved adding known amounts of acetic acid to aqueous bio-oil, was performed to verify whether the TAN analysis can accurately recover the mass of acetic acid added to aqueous bio-oil. Since known amounts of acetic acid were added to the aqueous bio-oil sample, the TAN values of aqueous bio-oil samples should be directly related to the 491 increasing acetic acid concentration.

Results from the TAN and HPLC analyses of aqueous bio-oil samples with added acetic acid are

494 presented in Figure 6. To incorporate the dilution effect after adding acetic acid solution, 90\% of the 495 measured TAN of the aqueous bio-oil (the first data point) was plotted with the measured TAN of 496 aqueous bio-oil samples with acetic acid added, displayed by black circular markers in Figure 6. To 497 incorporate the dilution effect due to added acetic acid solution, 90\% of the measured TAN of the 498 aqueous bio-oil was plotted with the measured TAN of aqueous bio-oil samples with acetic acid added, 499 displayed by black circular markers in Figure 6. The samples (overall 2, 4, and 6 wt\% of acetic acid in 500 aqueous bio-oil) were prepared with $90 \%$ of aqueous bio-oil and $10 \%$ of the acetic acid solution as 501 described in Section 2.2.4. The first data point (black circle marker) represents the aqueous bio-oil 502 without any acetic acid added, diluted by $10 \%$ with water to make it comparable with the other analyzed 503 samples that had acetic acid because those samples contained only $90 \%$ aqueous bio-oil. Based on the 504 measured TAN of the aqueous bio-oil and the measured TAN of the acetic acid standard solution from 505 Section 3.3, the calculated TAN values were estimated using Equation (7), similarly to Baig et al. [15], 506 and represented by a gray dashed line in Figure 6. The measured TAN values of aqueous bio-oil samples 507 were slightly higher than the calculated TAN values. The calculated TAN values, however, were still 508 within the range of measured TAN values, which are marked with error bars that indicate the standard 509 deviation. Moreover, the relationship of data points for aqueous bio-oil samples was linear with an $\mathrm{R}^{2}$ 510 value of 0.9963. 
512 The TAN analysis of aqueous bio-oil samples with added acetic acid led to less than $\pm 5 \%$ error,

513 calculated using Equation (2-b) and based on the calculated TAN from Equation (7).

514

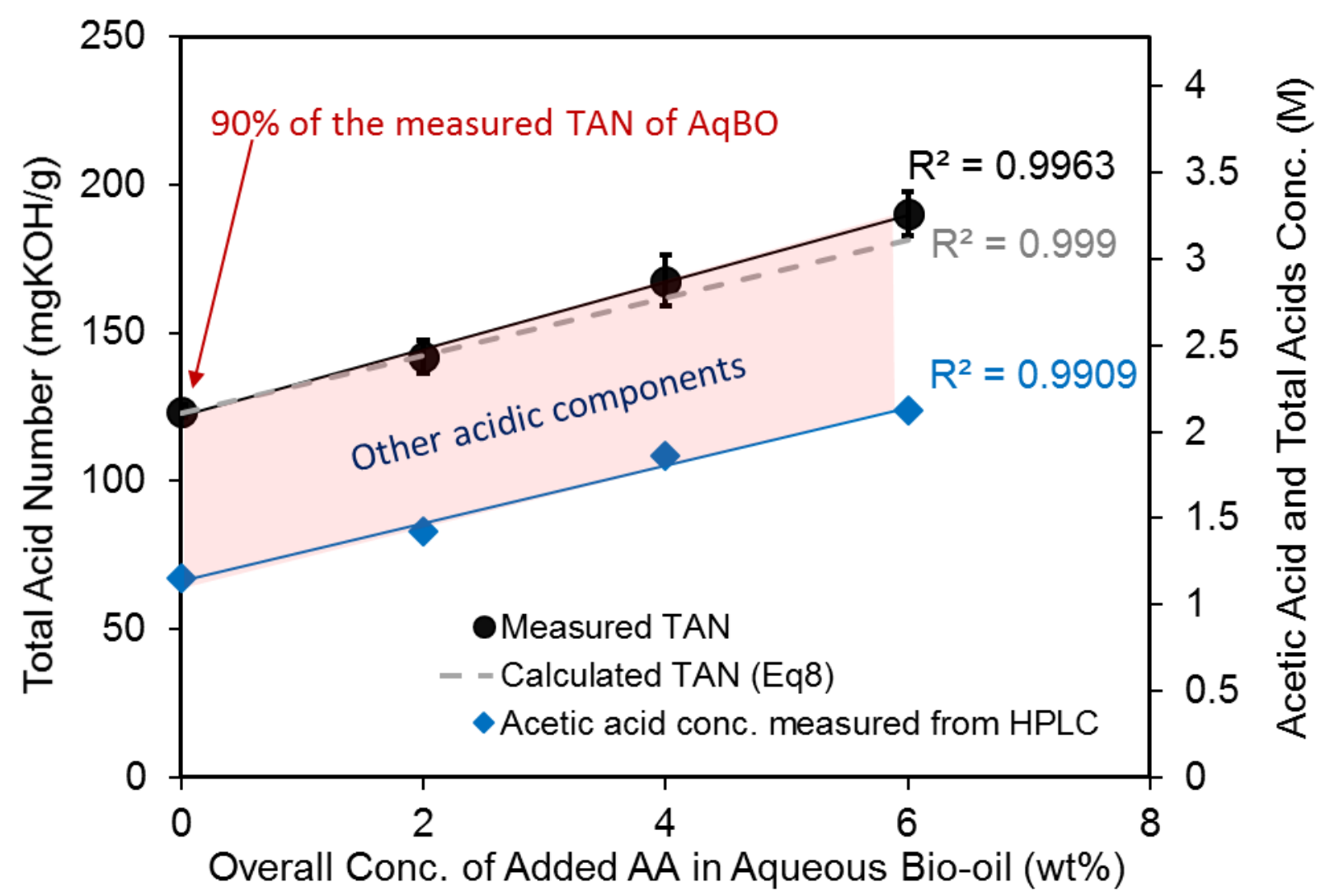

Figure 6. Measured TAN values of aqueous bio-oil (90\% of the value) and aqueous bio-oil samples with

517 known amounts of acetic acid added, calculated TAN of aqueous bio-oil samples using the measured

518 TAN values of aqueous bio-oil (90\%) and acetic acid standard solutions (2, 4, and 6 wt $\%)$ through

519 Equation (7) (broken line), and measured molar concentrations of acetic acid from HPLC analysis vs.

520 overall concentration of added acetic acid.

521

522 Calculated TAN $=[(\mathrm{TAN}$ of $\mathrm{AqBO}) \times(w t \%$ of $\mathrm{AqBO})+(\mathrm{TAN}$ of $\mathrm{AA}) \times(w t \%$ of $\mathrm{AA})] / 100$

523 AqBO: centrifuged or aqueous bio-oil, AA: acetic acid 
525 Aqueous bio-oil samples were also analyzed by HPLC to quantify the acetic acid concentration. The

526 molar concentrations of acetic acid in aqueous bio-oil samples were also included in Figure 6.

527 Chromatographs from the HPLC analysis are found in Figure 7. As expected, the concentration of acetic

528 acid detected by HPLC increased as more acetic acid was added to aqueous bio-oil samples. Using the

529 known relationship between TAN and molar concentrations of acetic acid solutions [Equation (5)], we

530 converted the molar concentrations of acetic acid in aqueous bio-oil samples to the TAN values,

531 represented as diamond markers in Figure 6. As shown in Figure 6, there is good agreement between

532 measured and calculated TAN values for different amounts of acetic acid added. Also, the differences

533 between TAN from total acids and TAN from acetic acid were consistent, as presented with the shaded

534 area. It may be noteworthy to mention that the concentrations of the shaded area may be overestimated

535 because some of these acidic components (e.g., vanillic acid) have a stronger effect on TAN values than

536 monoprotic acids. The consistent difference between total acids and acetic acid indicates that acidic

537 components, other than acetic acid, in aqueous bio-oil contributed similarly to the TAN value because no

538 other acidic components were added besides acetic acid. From the recovery test results, it can be

539 concluded that the presence of various chemicals, other than acetic acid, in bio-oil did not interfere the

540 detection of additional acetic acid. Moreover, the TAN values of bio-oil samples are proportional to the

541 amount of acetic acid present in bio-oil. In other words, the TAN values can reflect the amount of acetic

542 acid — the major acidic component present in switchgrass bio-oil. 


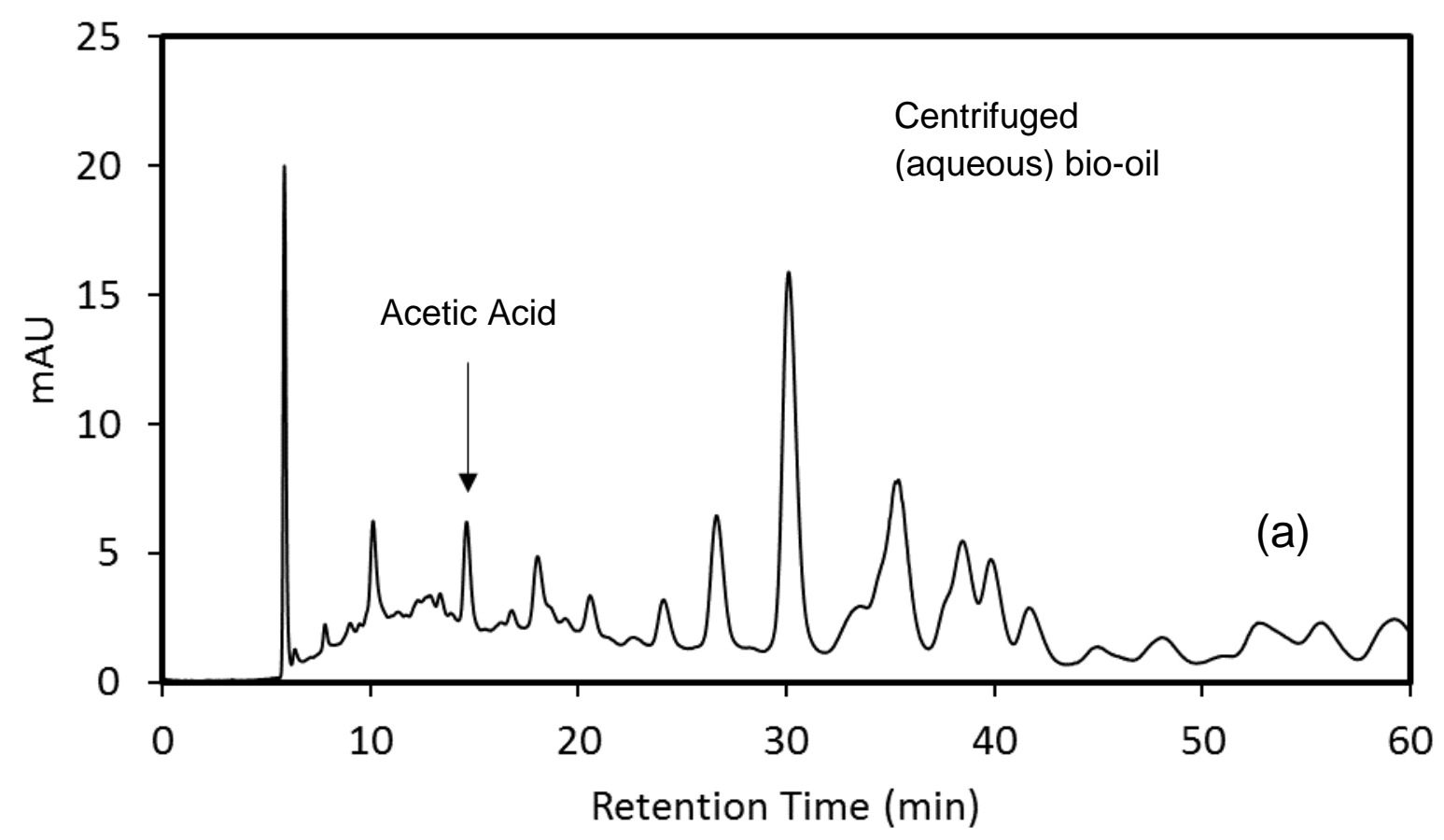

544

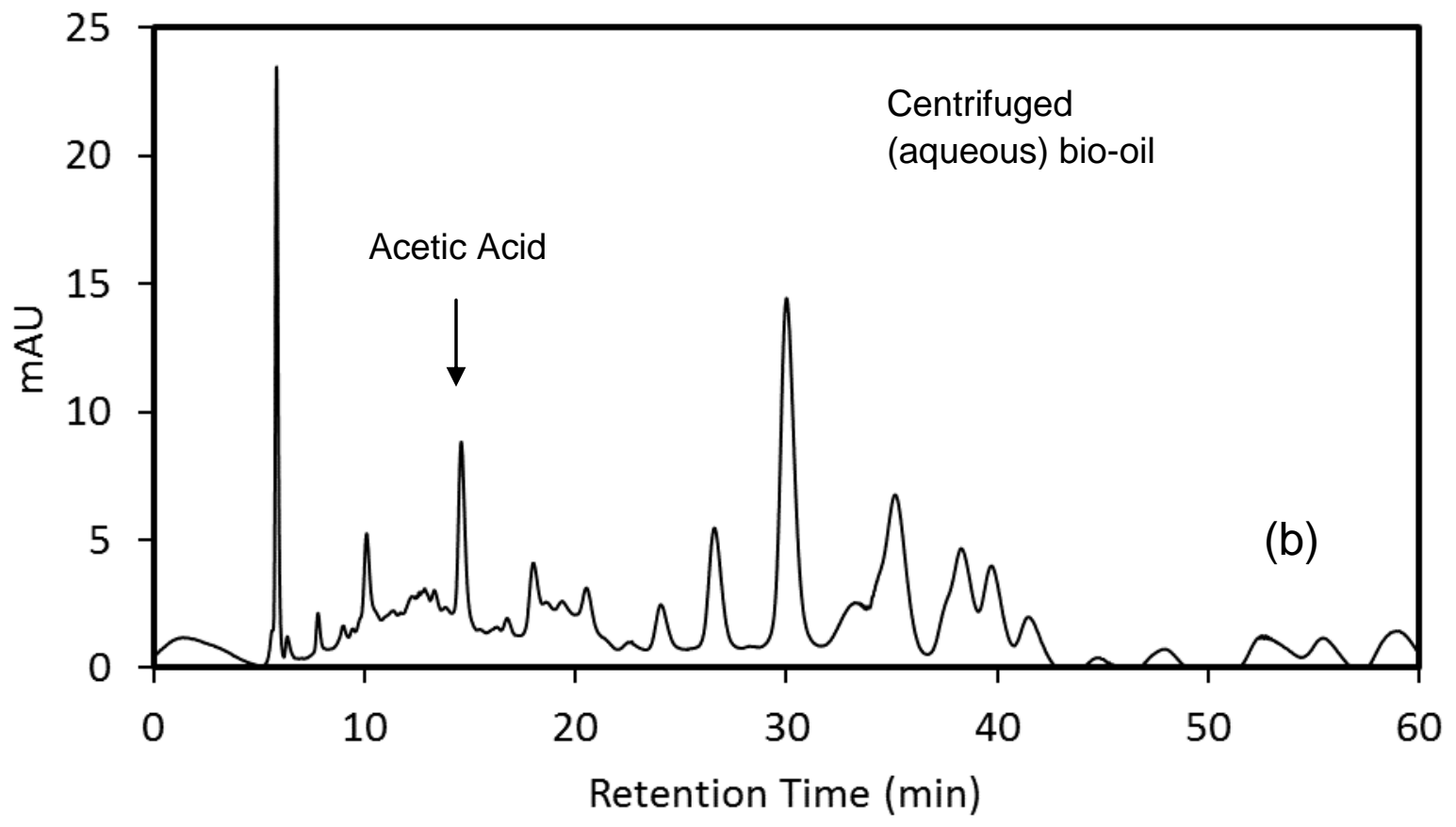




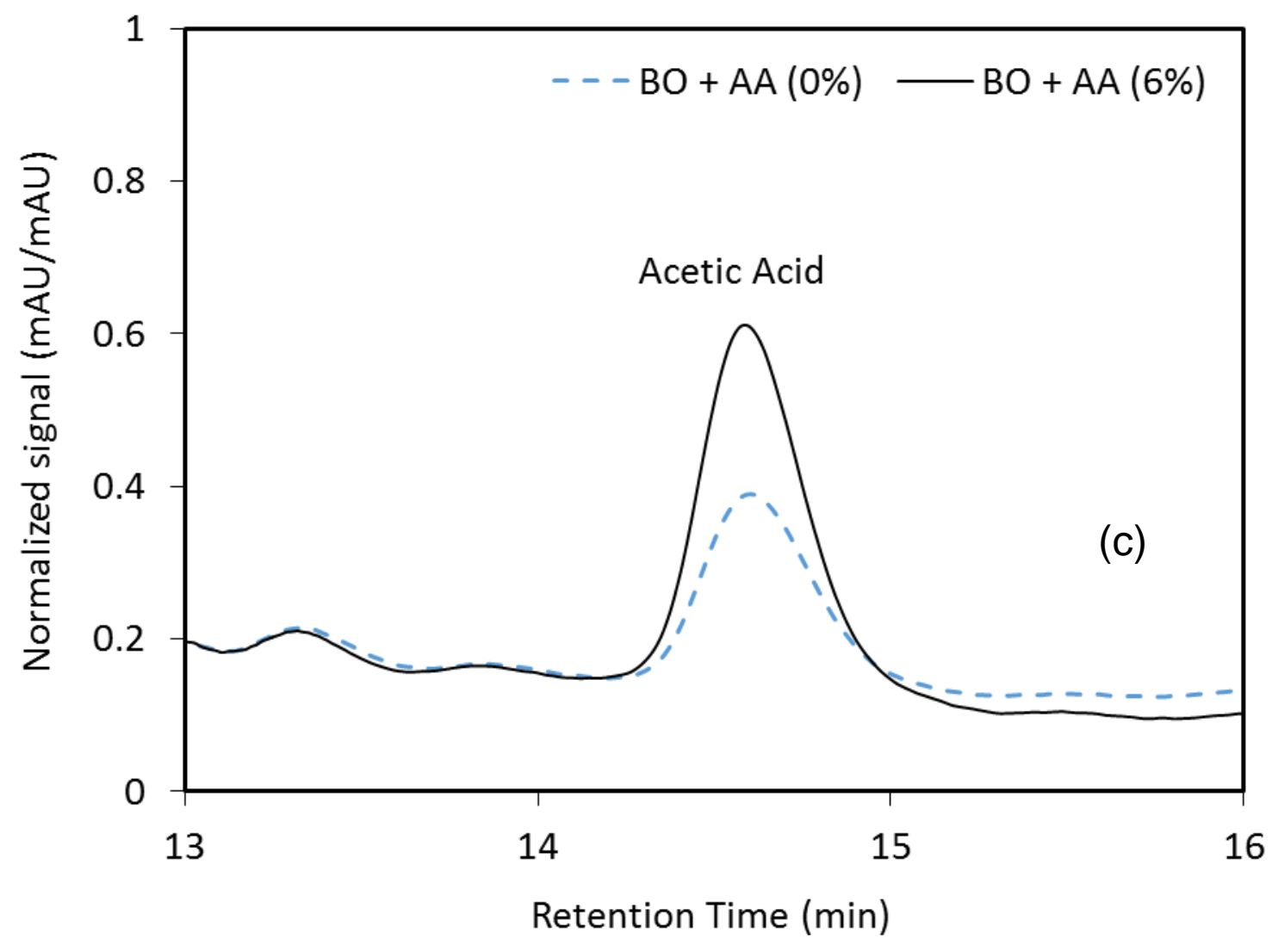

Figure 7. (a) HPLC chromatographs of aqueous bio-oil, (b) aqueous bio-oil with added acetic acid

548 (overall $6 \mathrm{wt} \%$ in aqueous bio-oil), and (c) zoomed-in view for acetic acid peaks from aqueous bio-oil

549 (dotted line) and aqueous bio-oil with added acetic acid (solid line).

551 Two major carboxylic acids - acetic and propionic acids - and other chemicals that contribute to the TAN

552 value of aqueous bio-oil are shown in Figure 8. It was found that $54 \%$ of the TAN value of the aqueous

553 bio-oil comes from the acetic acid. According to the chemical analysis of crude switchgrass bio-oil (prior

554 to centrifugation), the propionic acid content in the switchgrass bio-oil is roughly half of the acetic acid

555 content. Thus, assuming that the propionic acid content in the switchgrass bio-oil is half of the acetic acid

556 content, $27 \%$ of the TAN value should be attributed to propionic acid. The remaining $20 \%$ of the TAN

557 value is due to other chemicals, such as vanillic and syringic acids. The total molar concentration of other

558 chemicals may be smaller than the concentration of propionic and acetic acids, however, as shown in 
559 Section 3.3 from the TAN analysis of standard acids, the effects of these chemicals on the TAN value 560 may be important, showing a fraction of $20 \%$ in Figure 8.

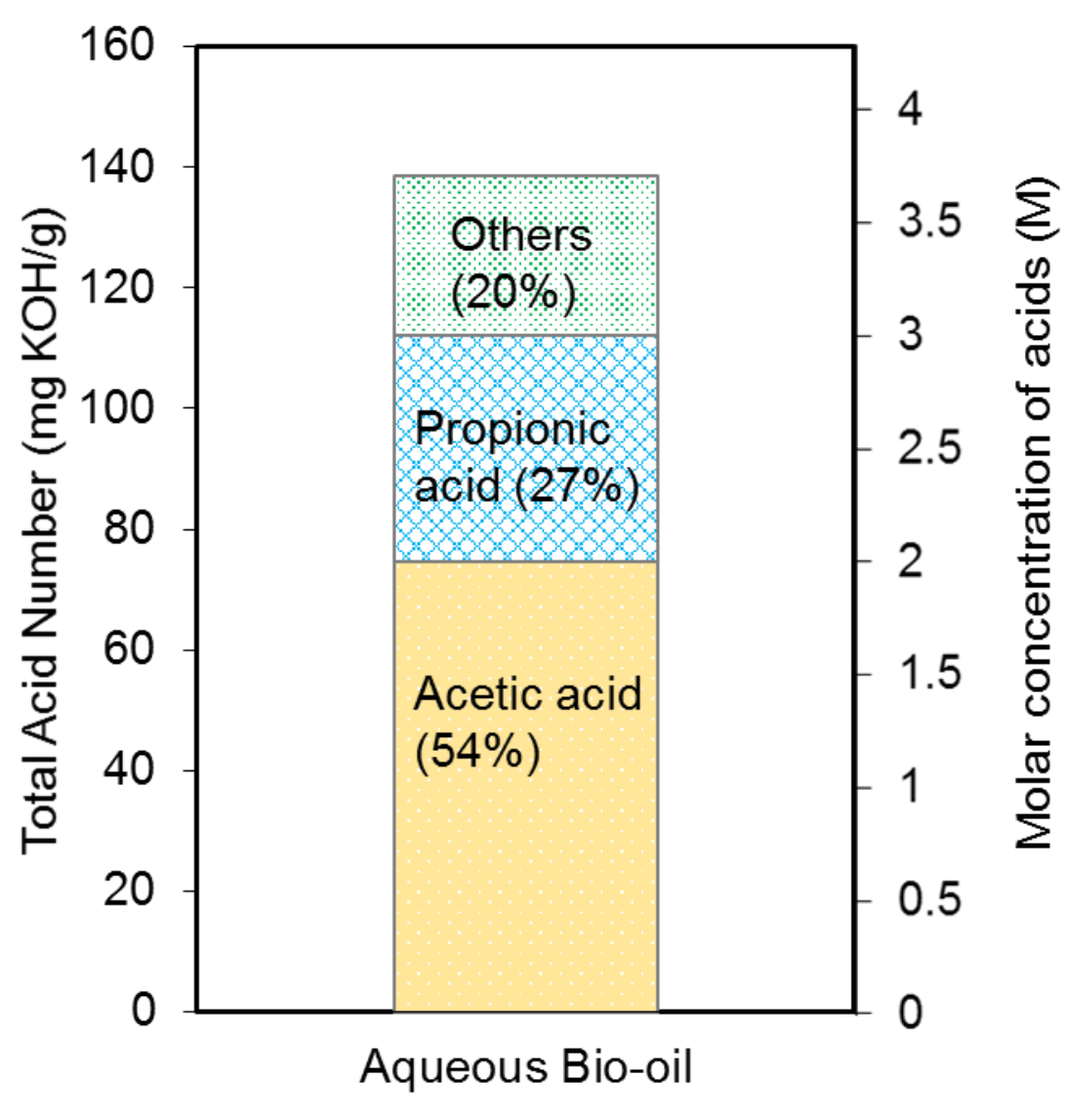

563 Figure 8. Carboxylic acids and other chemical components that contribute to the TAN value of the

564 aqueous bio-oil. The molar concentration equivalent to others (20\%) is overestimated in the graph

565 because chemical species other than acetic and propionic acids (e.g., vanillic acid) have a stronger effect

566 on the TAN value than monoprotic carboxylic acids.

\section{Conclusions}

569 This study investigated how monoprotic and diprotic acid bio-oil components contribute to the overall

570 acidity of bio-oils. An accepted ASTM potentiometric method for KOH titration of a variety of standard

571 samples and switchgrass aqueous bio-oil has been employed to yield the TAN value of the samples. The 
572 analyses were performed in triplicate using both aqueous and organic solvents. The bio-oil was separated

573 into aqueous and organic fractions by centrifugation and analyzed accordingly to provide consistent

574 measurements. An appropriate recovery analysis has also been performed.

576 A similar linear relationship was found between the TAN values vs. molar concentrations of acetic,

577 propionic, and hydroxybenzoic acids, which act as monoprotic acids in the titration solvent. This result

578 indicates that the TAN values can be converted to molar concentrations of total acids if a sample contains

579 only these acids. For more complex organic acid molecules that act as polyprotic acids during the TAN

580 analysis (e.g., vanillic and syringic acids), a higher slope of TAN values vs. molar concentrations was

581 obtained. The higher slope indicates a stronger contribution to the TAN value than that of chemicals

582 acting as monoprotic acids. The stronger effect on the TAN values from vanillic acid is interesting

583 because vanillic acid is considered a weaker acid than acetic and propionic acids. Thus, the TAN analysis

584 does not discriminate between weak and strong acids, since the respective protons are titrable. The TAN

585 analysis is, in general, an acceptable method to determine the acidity of bio-oil; however, a comparison of

586 TAN values of different types of bio-oil (produced from different sources of biomass or with various

587 pyrolysis settings) should take into consideration the type and concentration of acidic components in each

588 bio-oil. In other words, the standard TAN analysis method should be used with caution when we want to

589 compare different bio-oils.

591 Different titration curves and TAN values found for aqueous systems, both in modeling and experiments,

592 as expected, indicate that the $\mathrm{pK}_{\mathrm{a}}$ values in the standard titration solvent are different from those in

593 aqueous systems. These differences indicate different interactions and activities among chemical species

594 analyzed and titration solvent molecules. In a recovery test, the TAN values of aqueous bio-oil samples

595 increased proportionally to the amount of acetic acid added. Thus, the recovery test demonstrated that the

596 TAN value is proportional to the acetic acid content in bio-oil samples, and the various chemicals present

597 in AqBO do not interfere with the TAN analysis. This study demonstrates the usefulness of TAN analysis 
598 in determining the acidity of bio-oil before and after treatment and helps us understand how strongly

599 different bio-oil components contribute to the TAN value and, therefore, to the acidity of a complex

600 chemical system like bio-oil.

601

\section{Acknowledgements}

603 Funding for this work was provided by the Carbon, Hydrogen and Separation Efficiencies (CHASE)

604 program of the BioEnergy Technologies Office of the U. S. Department of Energy. The manuscript has

605 been co-authored by UT-Battelle, LLC, under Contract No. DEAC05-00OR22725 with the U.S.

606 Department of Energy. The authors thank Dr. Shoujie Ren, Dr. Pyoungchung Kim, Dr. Niki Labbe and

607 Dr. Philip X. Ye of the University of Tennessee for providing switchgrass bio-oil, Dr. Xiaofei (Sophie)

608 Zeng and Dr. Spyros G. Pavlostathis of the Georgia Institute of Technology for assistance with HPLC

609 analysis, and Mr. Alexander I. Wiechert of the Georgia Institute of Technology for editing the manuscript.

610

611 References

612 [1] M. Garcia-Perez, T.T. Adams, J.W. Goodrum, D.P. Geller, K. Das, Production and fuel properties of

613 pine chip bio-oil/biodiesel blends, Energy \& Fuels, 21 (2007) 2363-2372.

614 [2] D. Chiaramonti, A. Oasmaa, Y. Solantausta, Power generation using fast pyrolysis liquids from

615 biomass, Renew Sust Energ Rev, 11 (2007) 1056-1086.

616 [3] A.V. Bridgwater, D. Meier, D. Radlein, An overview of fast pyrolysis of biomass, Organic

617 Geochemistry, 30 (1999) 1479-1493.

618 [4] A. Oasmaa, D.C. Elliott, J. Korhonen, Acidity of Biomass Fast Pyrolysis Bio-oils, Energy \& Fuels, 24

619 (2010) 6548-6554.

620 [5] S. Ren, X.P. Ye, A.P. Borole, P. Kim, N. Labbé, Analysis of switchgrass-derived bio-oil and

621 associated aqueous phase generated in a semi-pilot scale auger pyrolyzer, Journal of Analytical and

622 Applied Pyrolysis, 119 (2016) 97-103. 
623 [6] J.-J. Wang, J. Chang, J. Fan, Upgrading of bio-oil by catalytic esterification and determination of acid 624 number for evaluating esterification degree, Energy \& Fuels, 24 (2010) 3251-3255.

625 [7] L. Moens, S.K. Black, M.D. Myers, S. Czernik, Study of the neutralization and stabilization of a 626 mixed hardwood bio-oil, Energy \& Fuels, 23 (2009) 2695-2699.

627 [8] L.K.-E. Park, S. Ren, S. Yiacoumi, X.P. Ye, A.P. Borole, C. Tsouris, Separation of Switchgrass Bio628 Oil by Water/Organic Solvent Addition and pH Adjustment, Energy \& Fuels, 30 (2016) 2164-2173.

629 [9] A. Oasmaa, D. Meier, Norms and standards for fast pyrolysis liquids: 1. Round robin test, Journal of 630 Analytical and Applied Pyrolysis, 73 (2005) 323-334.

631 [10] M.R. Rover, P.A. Johnston, B.P. Lamsal, R.C. Brown, Total water-soluble sugars quantification in 632 bio-oil using the phenol-sulfuric acid assay, Journal of Analytical and Applied Pyrolysis, 104 (2013) 194633201.

634 [11] Ion Exchange Chromatography, Bio-Rad. http://www.bio-rad.com/en-us/applications-

635 technologies/liquid-chromatography-principles/ion-exchange-chromatography.

636 [12] L. Wu, X. Hu, D. Mourant, Y. Wang, C. Kelly, M. Garcia-Perez, M. He, C.-Z. Li, Quantification of

637 strong and weak acidities in bio-oil via non-aqueous potentiometric titration, Fuel, 115 (2014) 652-657.

638 [13] K.D. Altria, Overview of capillary electrophoresis and capillary electrochromatography, Journal of

639 Chromatography A, 856 (1999) 443-463.

640 [14] J.A. Aricetti, M. Tubino, A green and simple visual method for the determination of the acid-number 641 of biodiesel, Fuel, 95 (2012) 659-661.

642 [15] A. Baig, F.T. Ng, Determination of acid number of biodiesel and biodiesel blends, Journal of the 643 American Oil Chemists' Society, 88 (2011) 243-253.

644 [16] A. Baig, M. Paszti, F.T.T. Ng, A simple and green analytical method for acid number analysis of 645 biodiesel and biodiesel blends based on potentiometric technique, Fuel, 104 (2013) 426-432.

646 [17] F. Barbieri Gonzaga, S. Pereira Sobral, A new method for determining the acid number of biodiesel 647 based on coulometric titration, Talanta, 97 (2012) 199-203. 
648 [18] V. del Río, M.S. Larrechi, M.P. Callao, Sequential injection titration method using second-order

649 signals: Determination of acidity in plant oils and biodiesel samples, Talanta, 81 (2010) 1572-1577.

650 [19] M. Gonçalves, K. Cunha, S. Sobral, F. Gonzaga, I. Fraga, P. Borges, Acid Number Determination of 651 Biodiesel by Potentiometric Titration Using Different Methods, Biofuels, ASTM International, 2011.

652 [20] G. Knothe, Analyzing biodiesel: standards and other methods, Journal of the American Oil Chemists' 653 Society, 83 (2006) 823-833.

654 [21] K. Komers, F. Skopal, R. Stloukal, Determination of the Neutralization Number for Biodiesel Fuel 655 Production, Lipid / Fett, 99 (1997) 52-54.

656 [22] S. Mahajan, S.K. Konar, Determining the acid number of biodiesel, Journal of the American Oil

657 Chemists' Society, 83 (2006) 567-570.

658 [23] M. Tubino, J.A. Aricetti, A green method for determination of acid number of biodiesel, Journal of 659 the Brazilian Chemical Society, 22 (2011) 1073-1081.

660 [24] M. Tubino, J.A. Aricetti, A green potentiometric method for determination of the acid number of oils 661 and fats, Journal of the Brazilian Chemical Society, 24 (2013) 1691-1696.

662 [25] R. Kauffman, Rapid, portable voltammetric techniques for performing antioxidant, total acid number 663 (TAN) and total base number (TBN) measurements, Tribology \& Lubrication Technology, 54 (1998) 39.

664 [26] B. Fuhr, B. Banjac, T. Blackmore, P. Rahimi, Applicability of Total Acid Number Analysis to Heavy 665 Oils and Bitumens, Energy \& Fuels, 21 (2007) 1322-1324.

666 [27] D. Chen, J. Zhou, Q. Zhang, X. Zhu, Evaluation methods and research progresses in bio-oil storage 667 stability, Renewable and Sustainable Energy Reviews, 40 (2014) 69-79.

668 [28] ASTM D664. Standard Test Method for Acid Number of Petroleum Products by Potentiometric 669 Titration, American Society for Testing Materials (ASTM) International, West Conshohocken, PA, 2011. 670 [29] ASTM D974-14e2. Standard Test Method for Acid and Base Number by Color-Indicator Titration, 671 American Society for Testing Materials (ASTM) International, West Conshohocken, PA, 2014. 
672 [30] ASTM D3339-12. Standard Test Method for Acid Number of Petroleum Products by Semi-Micro

673 Color Indicator Titration, American Society for Testing Materials (ASTM) International, West

674 Conshohocken, PA, 2012.

675 [31] AOCS Cd 3d-63. Acid Value, The American Oil Chemists' Society, Urbana, IL 2009.

676 [32] EN140104. Fat and oil derivatives - Fatty Acid Methyl Esters (FAME) - Determination of acid value 677 European Standard, 2003.

678 [33] The Theory of pH Measurement, Emerson Process Management, Irvine, CA, 2010, pp. 1-7.

679 [34] J. Shao, F. Agblevor, New Rapid Method for the Determination of Total Acid Number (Tan) of Bio680 Oils, American Journal of Biomass and Bioenergy, 4 (2015) 1-9.

681 [35] J. Wang, C. Xu, Q. Song, Rapid and Environmentally Friendly Three-Dimensional-Printed Flow

682 Injection Analysis System for the Determination of the Acid Number in Thermal Conductive Oil, Energy

683 \& Fuels, 29 (2015) 1040-1044.

684 [36] P. Kim, A. Johnson, C.W. Edmunds, M. Radosevich, F. Vogt, T.G. Rials, N. Labbé, Surface

685 Functionality and Carbon Structures in Lignocellulosic-Derived Biochars Produced by Fast Pyrolysis,

686 Energy \& Fuels, 25 (2011) 4693-4703.

687 [37] S. Ren, X.P. Ye, A.P. Borole, Separation of chemical groups from bio-oil water-extract via 688 sequential organic solvent extraction, Journal of Analytical and Applied Pyrolysis, 123 (2017) 30-39. 689 [38] ASTM D4377-00, Standard test method for water in crude oils by potentiometric Karl Fischer 690 titration, West Conshohocken, PA, 2011.

691 [39] Y. Zhang, F. Guo, Q. Cui, M. Lu, X. Song, H. Tang, Q. Li, Measurement and Correlation of the 692 Solubility of Vanillic Acid in Eight Pure and Water + Ethanol Mixed Solvents at Temperatures from 693 (293.15 to 323.15) K, Journal of Chemical \& Engineering Data, 61 (2016) 420-429.

694 [40] H. Wang, H. Tang, J. Wilson, S.O. Salley, K.Y.S. Ng, Total Acid Number Determination of 695 Biodiesel and Biodiesel Blends, Journal of the American Oil Chemists' Society, 85 (2008) 1083-1086.

696 [41] Calculation, Chemicalize - Instant Cheminformatics Solutions, ChemAxon, Ltd, 2016.

697 http://www.chemicalize.org 
698 [42] F. Liu, S. Sivoththaman, Z. Tan, Solvent extraction of 5-HMF from simulated hydrothermal 699 conversion product, Sustainable Environment Research, 24 (2014).

700 